\title{
Social (-Ecological) Network Analysis in Environmental Governance: Central Publications, Important Concepts, and Areas of Application
}

\author{
Theresa Schwenke ${ }^{1}$ \\ Social-Ecological Systems Analysis Working Group, Social Science Department, \\ Leibniz Centre for Tropical Marine Research, Bremen, Germany \\ Eike Holzkämper \\ Social-Ecological Systems Analysis Working Group, Social Science Department, \\ Leibniz Centre for Tropical Marine Research, Bremen, Germany
}

\section{Abstract}

Social and social-ecological network analysis (S(E)NA) have recently emerged as new methods in the environmental governance (EG) literature. By investigating networks of connections between actors, $S(E) N A$ advances the understanding of who is involved in EG and how. We provide an overview of the EG literature applying $S(E) N A$ and map (1) the citation network emerging from cross-references and (2) the similarity network emerging from word similarities between publications. We show that S(E)NA application in EG is in the process of developing into a field of research where publications frequently cite each other. We identify 20 publications which occupy positions as sources, storers, or bridges of knowledge in the citation network. While we see S(E)NA applied in diverse resource contexts, these are mainly discussed on the local spatial level, with a focus on "policy" or "collaboration." We discover that "power structures" and "the production of knowledge" are themes influencing the whole field.

Keywords: bibliometric network analysis, environmental management, Latent Dirichlet Allocation, social network analysis, topic detection.

1 Corresponding author: theresa.schwenke@leibniz-zmt.de. 


\section{Introduction: Applying social network analysis in environmental governance}

The growing impact of human activities on the geo-bio-physical environment has led to the dawn of the Anthropocene, where alarming developments like climate change, ecosystem degradation, and unsustainable resource exploitation dramatically affect the populations that depend directly on the ecosystem they live in (Glaeser, 2016), and favor feedbacks between ecological and social systems that trigger global crises (Wijkman \& Rockström, 2013). Facing these worrying-and likely intensifying - trends, the question of how to govern the human use of the geo-bio-physical environment is ever more salient (Young, 2016).

Environmental governance (EG) is a field of research that aims to improve our understanding of human-nature relations and to develop evidence-based recommendations on how to balance ecological with social needs. The field traditionally focuses on the human use of the geo-bio-physical environment, which is often challenged by (anthropogenic or other) threats. The geo-bio-physical environment encompasses the environmental goods and services or "resources ... at stake" (Borrini-Feyerabend, 2011) like the climate, biodiversity, freshwater, oceans, forests, wildlife, air, and land (Paavola, 2007). Natural resources and ecosystem services explicitly include immaterial goods such as knowledge, learning, and recreational or aesthetic values (Chiesura \& Groot, 2003).

EG investigates societal decision-making processes and institutions steering human behavior regarding the use of the geo-bio-physical environment (Armitage et al., 2012). It focuses on structures and processes that guide how humans interact with each other, make decisions, and pursue their (often conflicting) interests regarding environmental goods and services. These structures and processes encompass formal (e.g., legal frameworks, government regulations, officially responsible organizations) or informal (e.g., social pressure, values, norms, market forces) institutions that influence environmental agendas and decision-making. EG comprises development, function, and change of these institutions, as well as decisions themselves and the measures taken to implement them (Armitage et al., 2012).

Management is often used interchangeably with "governance." While both are closely interrelated, they are different concepts (Armitage et al., 2012). Management deals with technical issues like operational decisions, rule implementation, and monitoring specifications. It is about the procedural "what to do?" (Borrini-Feyerabend, 2011) with the managed aspects of the natural geo-bio-physical environment.

Governance emerges when various social actors from public, market, and civic spheres (such as government agencies, businesses, nongovernmental organizations [NGOs], and local communities) focus around a problem to address challenges and 
resolve conflicts while advocating their respective agendas (Lee, 2003). Governance implies a certain share of power between the different spheres as it actively involves different societal actors in public decision-making (Lebel et al., 2006). It can be seen as a "continuum of systems of governing, in which state and non-state actors play a variety of roles" (Bulkeley, 2005, p. 877). Governance is about "who decides what to do and how?" (Borrini-Feyerabend, 2011), as well as who should execute the how (Glasbergen, 1998). Thereby it provides "the context that enables management" (Alexander, 2015), which means "the essential direction, resources, and structure needed to meet the overarching resource governance goals" (Crona et al., 2011, p. 45). Management is thus an essential, but not sufficient, part of governance. Management concepts like co-management, collaborative management, participatory management, and community-based management involve a variety of societal actors which share decision-making power. Therefore these concepts actually refer to systems of governance as defined above. Table A in the supplemental material for this article (Schwenke \& Holzkämper, 2020) provides a short overview of some of the actors and types of governance found in the EG literature. ${ }^{2}$

The challenges characteristically addressed by EG exceed typical sectoral, spatial, and disciplinary boundaries, making them complex and wicked problems (Balint et al., 2011). Recently, the application of a new method emerged in the EG literature: social network analysis (SNA). SNA is an analytical tool to mathematically describe, visualize, and investigate the networks of connections between social actors. The method advances the understanding of who is involved in governance processes (and who is not), as well as what type of relations and interactions connect governance actors. But SNA is more than just a method; it is the application of a network perspective by analyzing through the lens of social relations. The basis of SNA is the modeling of social actors as nodes that are connected by links representing the relations between these actors. Actors can be individual or collective social entities and connections between actors are social relations such as friendship or kinship ties, interactions (e.g., advice-seeking), or similarities (e.g., membership). Nodes and links together form a unique network structure at one point in time (Alexander, 2015). Thus, the number of actors and connections becomes quantifiable, offering opportunities for the mathematical investigation of the structure of social relations as networks (Marin \& Wellman, 2014). The graphical network visualization provides additional opportunities for analytical explorations (Venturini et al., 2015). In an effort to reduce complex interrelations to an analyzable degree, SNA examines actors and their connections within specific contexts (such as EG) and defined boundaries that set the frame for the network data collection. Today, SNA is endorsed by a broad spectrum of disciplines in the social and natural sciences, and the study of networks was in turn influenced by ideas from many of these areas. The analysis of EG as

2 See file: Schwenke\&Holzkaemper_SENA in EG Table A_Governance types.pdf (Schwenke \& Holzkämper, 2020). 
networks of connections between societal actors has emerged as a "powerful and practical tool" for the study of EG issues (Alexander, 2015). EG networks are one type of context-specific network that are exogenously built and/or endogenously form around a governance issue, such as the use or conservation of the geobio-physical environment (Borrini-Feyerabend, 2011). These networks usually involve actors at the organizational level from different social realms (e.g., NGOs, government agencies, or businesses). Acknowledging the manifold interlinkages of humanity with its geo-bio-physical environment, which are of special importance for EG related questions, an area of network science emerged that includes ecological entities: the social-ecological network (SEN) approach. This approach assumes that social-ecological systems can be investigated, analyzed, and modeled as SENs. It expands the classical SNA, which focuses on social actors, by adding non-human actors (e.g., ecological resources) and their interdependencies. Ideally, a socialecological network analysis, or S(E)NA, includes all possible types of links within the system: (1) social-to-social, (2) social-to-ecological, (3) ecological-to-ecological, and (4) ecological-to-social (Bodin \& Tengö, 2012). The inclusion of non-human actors in the network analysis of EG topics is a valuable addition to traditional SNA methods and increases our understanding of EG.

To our knowledge, there have been no previous studies which provide an overview of or investigate bibliometric patterns within the scientific literature applying S(E) NA approaches in EG. We conduct a Web of Science search and show the growing body of literature within the research fields EG and S(E)NA and provide first insights to the question if the use of S(E)NA in EG is developing into a distinct research field. We then analyze the intersection of both fields by investigating (1) the structure of the citation network emerging from cross-references of publications and (2) the similarity network emerging from word similarities between publications. We provide visualizations of both networks and discuss their structural elements to tackle our main research questions: (1) In which peer-reviewed publications is $S(E)$ NA applied to investigate EG issues? (2) Is the body of literature applying S(E)NA in EG interconnected by a network of direct citations between publications, thus indicating the formation of an individual subfield of research? (3) If so, what are influential publications for the development of the subfield? (4) Which EG related topics are frequently addressed by applying S(E)NA?

\section{Methods}

Scientific progress, such as the generation of insights into EG by applying S(E)NA, takes place through the production and propagation of knowledge. An essential (although not sufficient) part of this process is the exchange of ideas and knowledge among academia. Databases of peer-reviewed literature (e.g., Web of Science) record the flows of knowledge which are associated with citation processes. A citation 
between two publications occurs when one publication refers to another as a source of knowledge. It thus establishes a documented, formal communication channel between these two publications (Shaw, 1981). The publication which is sending a link is then called the citing publication, while the publication which is receiving a link is referred to as the cited publication. The patterns of citing and being cited can be depicted as a citation network with publications as nodes and citations as links. The emerging network structure visualizes the communication system of contemporary science based on citations in peer-reviewed literature and can be used to reveal the "intellectual linkage" of articles (Barnett et al., 2011). Small et al. (2014) have shown that citation-based methodologies can be used to identify emerging topics in science.

While "similar citation patterns ... represent similarities of academic perceptions and opinions" (Barnett et al., 2011), the second approach to cluster a body of publications considered in this research is a more direct indication of similarity between publications. The similarity network approach defines a relation between two publications based on the similarity of their texts, rather than on citation processes between them. In a similarity network, publications are nodes. A link between two nodes indicates a certain level of text similarity between these, identified by shared words found in both publications. In conjunction with topic detection methods, clustering a body of literature by text similarity adds a different, topiccentered perspective to a bibliometric analysis.

We investigate the body of literature applying S(E)NA in EG in two ways: by conducting (1) a citation network analysis and (2) a similarity network analysis including topic detection. We further assess the importance of publications within the body of literature by their position in the citation and similarity network. Table 1 gives an overview of the network metrics we applied and their meanings in the context of a citation or similarity network, respectively.

Because publications within a module in a similarity network likely address similar information content, clustering a publication similarity network into modules can be employed to detect topics from texts (Larsen \& Aone, 1999). The detection of topics for modules adds meaning to the network structure and describes how a research field is structured topically. Words that describe a topic very likely occur more often in a publication's text than other words (after eliminating stop words ${ }^{3}$ ). Under this assumption, word frequency can identify topics of publications. Similarly, the frequency of publication topics in a module of publications can identify the general topic for the complete module.

3 Stop words (e.g., I, and, of) are common in all kinds of text, irrespective of its content. 


\section{Table 1. Network metrics applied in this study and their interpretation in (A) a citation network and (B) a similarity network.}

\begin{tabular}{|c|c|}
\hline (A) Metric and reference & terpretation in a citation network \\
\hline $\begin{array}{l}\text { Modularity: partitions the network } \\
\text { into groups of nodes that are } \\
\text { densely connected among each } \\
\text { other and sparsely connected to } \\
\text { other groups (Blondel et al., 2008). }\end{array}$ & $\begin{array}{l}\text { Modules are groups of publications in which knowledge } \\
\text { circulates: in a citation network, publications cite each } \\
\text { other frequently while they refer to few publications outside } \\
\text { the module they are part of (Baggio et al., 2015). }\end{array}$ \\
\hline $\begin{array}{l}\text { HITS (hyperlink-induced topic } \\
\text { search): ranks publications by } \\
\text { the number and quality of their } \\
\text { citation links; identifies hubs and } \\
\text { authorities (Kleinberg, 1999). }\end{array}$ & $\begin{array}{l}\text { The HITS algorithm was originally developed to assess a } \\
\text { website's significance in an interlinked (web)space. It is also } \\
\text { applied in bibliometric analyses. Highly cited documents } \\
\text { are called "authorities" and are often referred to as sources } \\
\text { of knowledge. They propagate highly significant content } \\
\text { for the research community. Highly citing documents, also } \\
\text { referred to as storers of knowledge, are called "hubs." They } \\
\text { refer to many sources of knowledge (authorities) and are } \\
\text { very likely review papers. A good hub points to many good } \\
\text { authorities; a good authority points to many good hubs. }\end{array}$ \\
\hline $\begin{array}{l}\text { Betweenness centrality }(\mathrm{BC}) \text { : } \\
\text { measures the importance of } \\
\text { a node in a network based on } \\
\text { its position between modules } \\
\text { (Freeman et al., 1991). }\end{array}$ & $\begin{array}{l}\text { A BC-high publication is an important paper bridging the } \\
\text { flow of scientific knowledge between different schools } \\
\text { of thought or disciplines. BC thus is an indicator for the } \\
\text { degree of interdisciplinary connections (Leydesdorff, 2007). }\end{array}$ \\
\hline (B) Metric and reference & Interpretation in a similarity network \\
\hline $\begin{array}{l}\text { Modularity: partitions the network } \\
\text { into groups of nodes that are } \\
\text { densely connected among each } \\
\text { other and only sparsely connected } \\
\text { to other groups (Blondel et al., } \\
\text { 2008). }\end{array}$ & $\begin{array}{l}\text { In a similarity network, modules are groups of publications } \\
\text { that share similar text. Analyzing modularity means } \\
\text { organizing a considerable number of data objects in a } \\
\text { network into a smaller number of coherent groups. It can } \\
\text { thus give an overview and aid in the exploration of large } \\
\text { data sets such as a body of literature (Huang, 2008). }\end{array}$ \\
\hline $\begin{array}{l}\text { Degree centrality: counts the } \\
\text { number of nodes a node is linked } \\
\text { to (Freeman, 1978). }\end{array}$ & $\begin{array}{l}\text { In a similarity network, high degree centrality indicates } \\
\text { that the publication shares word similarity with many other } \\
\text { publications. }\end{array}$ \\
\hline
\end{tabular}

Note: HITS = hyperlink-induced topic search; BC = betweenness centrality.

Source: See citations throughout table.

In Figure 1, we provide an overview of the workflow and the software we used. After data collection, the body of literature is analyzed in two ways: by investigating (1) the citation network and (2) the similarity network between publications. The steps to analyze both citation and similarity network can be roughly divided into: creation of the networks, calculation of network measures, and visualization of the network. We give a detailed description of each step below. In addition to the workflow shown in Figure 1, we also applied the Latent Dirichlet Allocation (LDA) as a second method to detect topics within our collection of literature (see 2.3.7). 


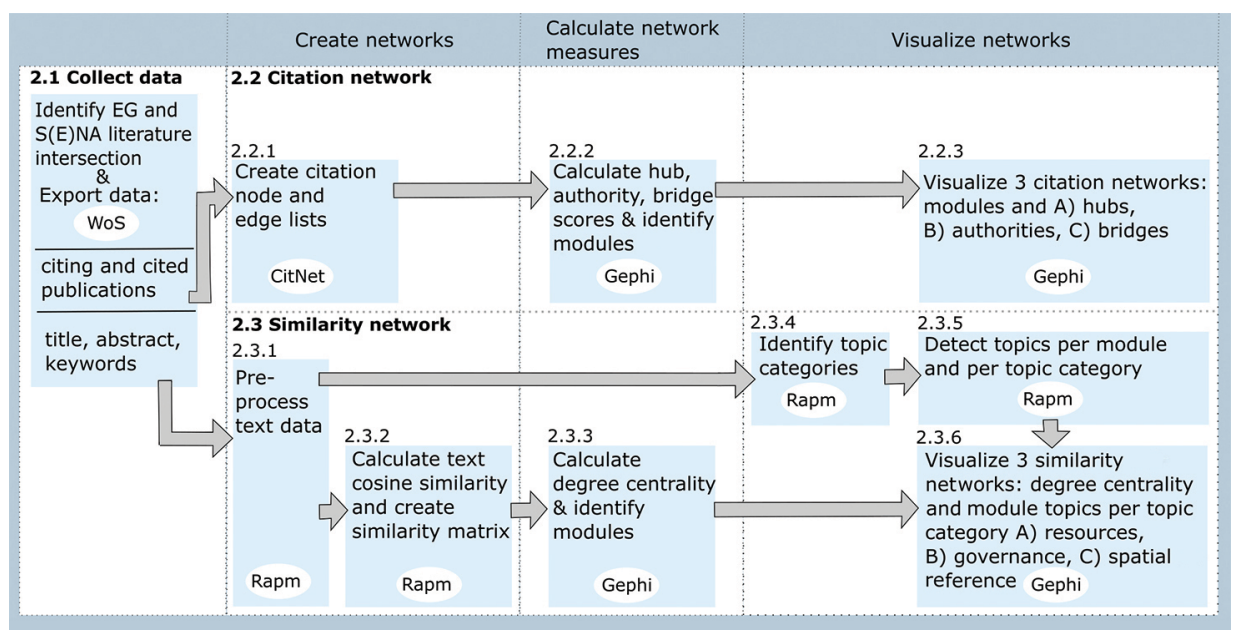

Figure 1. Workflow to map the use of $S(E) N A$ in EG by combining a document similarity and a citation network analysis.

Note: CitNet = CitNet Explorer (van Eck \& Waltmann, 2014); WoS = Web of Science online tool (ISI Thomson Reuters); Rapm = RapidMiner Studio 9.3 (Mierswa \& Klinkenberg, 2018); Gephi = Gephi 0.9.2 (Bastian et al., 2009).

Source: Authors' description of workflow.

\subsection{Data collection}

We queried the Web of Science database (ISI Thomson Reuters) to identify academic literature with an explicit focus on EG, S(E)NA, or both. For this, we used two separate search strings: (1) a combination of "environmental" and "governance" search terms to identify the body of literature relating to the EG field, and (2) "social and social-ecological network analysis" search terms to identify the body of literature relating to the research field S(E)NA. Our search query included terms that identify EG and S(E)NA after our definition in the introduction and under the acknowledgment of common synonyms - the full list of search terms is in the supplemental material. ${ }^{4}$ We searched for articles that contain our search terms in title, keywords, or abstract. The time frame of the search was set from the earliest record to the end of the year 2018 and was limited to peer-reviewed articles, books, and book chapters in English language. We then filtered the search results for those publications that connect to both fields. The search results were stored as citation files (simple-text "full record and cited references" format, tab-delimited"), featuring the publications' titles, keywords, abstracts, author/s, and dates of publication, and including the full list of references each publication cites. Our search resulted in 69,463 EG related publications and 5,125 S(E)NA publications.

4 See file: Schwenke\&Holzkaemper_SENA in EG I\&II_Web of Science search syntax.pdf (Schwenke \& Holzkämper, 2020).

5 See file: Schwenke\&Holzkaemper_SENA in EG Table E_WoS search results.csv (Schwenke \& Holzkämper, 2020). 
For our further analysis, we consider the body of literature that intersects between our focus research themes EG and S(E)NA, which consists of 241 publications. In the citation network, we additionally show the 10 publications that were most frequently cited by the intersection, but not part of the intersection.

\subsection{Citation network}

\subsubsection{Creation of citation node and link list}

We imported the search results into CitNet Explorer (van Eck \& Waltman, 2014) and included "non-matching references" with a minimum number of 33 citations in our analysis. "Non-matching references" are those publications which are on the list of references of any of the publications in the original search results, but not part of the search results themselves. The matching of reference lists and search results in CitNet Explorer is done based on either DOI or the combination of first author's first name and first initial, publication year, volume number, and page number (van Eck \& Waltman, 2014). As our aim is to focus explicitly on the body of literature dealing with S(E)NA in EG, we chose to only include the 10 nonmatching references that are cited most frequently by our focus literature.

CitNet Explorer created a node list (publications) and a link list (citations between publications) from the information on cited and citing publications stored in the search results, while removing citation links that point forward in time or cause acyclicity $^{6}$ (van Eck \& Waltman, 2014). Node and link list together define the citation network.

\subsubsection{Calculation of citation network measures}

After importing the node and link lists into Gephi (Bastian et al., 2009), we used the HITS (hyperlink-induced topic search) algorithm (Kleinberg, 1999) to identify hubs and authorities, while betweenness centrality indicated where bridges were located (Table 1). We thereby identified publications which stood out by their position in the network. We read these publications to find out the concepts they deal with. We detected modules by applying the modularity optimization algorithm for directed networks (Blondel et al., 2008), with a resolution setting of 1.0.

\subsubsection{Visualization of the citation network}

While it is possible to visualize citation networks historiographically, displaying time at the $\mathrm{x}$-axis and arranging nodes accordingly (Garfield, 2004), we aim to focus on citation clusters rather than timelines. To visualize the citation network, we therefore used the "Force Atlas" algorithm, a spatialization algorithm from the force-vector family, which places nodes with stronger and/or more connections closer together

6 Acyclicity in a bibliographic network context refers to citation processes in which older publications cite more recent ones. 
and more central nodes to the center (Jacomy et al., 2014). We labeled nodes with "author_year." As newer papers often cite older papers, this label can indirectly also visualize the chronological order of citation (Nakazawa et al., 2018). We visualized different modules with different colors, and the "Non-matching references," as well as links pointing toward them, in light gray. In 2.2.2, we calculated values that assess the importance of publications as either hubs (A), authorities (B), or bridges (C). Consequently, we produced three distinct visualizations of the citation network, each visualizing one of these network measures as node size. The size of a node is proportional to its value, with larger nodes representing higher values. We selected the publications with the highest authority $(n=8)$ and hub scores $(n=8)$ and those with the highest betweenness values $(n=7)$ for an in-depth content analysis. For better visibility of the publications we consider in our content analysis, all other nodes were assigned a minimum size.

\subsection{Similarity network}

\subsubsection{Text data preprocessing}

We imported the search results from the data collection into RapidMiner (Mierswa \& Klinkenberg, 2018). Using RapidMiner, we assembled title, keywords, and abstract of each publication into one document per publication. We further treated these text attributes as a "bag of words," disregarding the semantic relationship of words (Zhang et al., 2010). Very small words are very likely either stop words or abbreviations. Both are unwanted words as they are not helpful to model documents in a meaningful way. To reduce this noise, we removed stop words and filtered out words smaller than four characters. For the remainder of the analysis, the "bag of words," containing only informative words from title, keywords, and abstract of each publication, was used to model publications. We call these publication models "documents."

\subsubsection{Calculation of the text cosine similarity and creation of the similarity matrix}

A similarity matrix is an adjacency matrix which represents a network between publication models based on their word similarity. To create the similarity matrix, we used the documents which resulted from Step 2.3.1. and applied the vector space model (Larsen \& Aone, 1999) to these documents. More explicitly, we counted the occurrence of words for each document, and each word corresponded to a dimension in a resulting data space. Each document became a vector consisting of word frequency values on each dimension (i.e., each word). ${ }^{7}$ When documents are represented as vectors, we can measure the degree of similarity of two documents as the correlation between their corresponding vectors. This measure is quantified

7 See file: Schwenke\&Holzkaemper_SENA in EG III_VectorRepresentation.pdf (Schwenke \& Holzkämper, 2020). 
by the cosine of the angle between the two vectors, thus called cosine similarity (Huang, 2008). The similarity network consists of $\mathrm{n}$ (number of documents) nodes and $\mathrm{n}^{*} \mathrm{n}$ similarity links between nodes, weighted by the cosine similarity with possible values between 1 and 0 . A cosine similarity of 1 means an identical replication of the document in terms of word occurrence. A similarity link scoring 0 can be excluded from a similarity network, as it means "no similarity at all." For texts of the same language, however, the cosine similarity will almost never be 0 . Thus, similarity networks of documents of the same language, and based on the cosine, often result in a network with a density equal 1 , which means that every node is linked to every other node. Such a network does not display any structural features. Yet it is our intention to represent the documents in a meaningful network structure. We therefore set a threshold for the level of similarity that we still consider as forming a similarity link. Due to the very specific research question and search query, we assumed that the identified publications already have a high level of similarity - therefore we chose a rather low similarity threshold to still include all relevant relations. The step of selecting the threshold was aided by a visualization of the similarity network. The network started to form distinct clusters at a threshold for the cosine similarity of 0.1 , removing links between documents that show less than 10 percent similarity. The value setting of the threshold was sufficiently low to still show important connections between documents. This procedure also produced isolates which no longer shared any connection with the main network. By the logic inherent in the cosine similarity, we assumed that the isolates of the similarity network distinctly differ from the rest of the network in their contents. We read the abstracts of these isolates to assess their relevance for our body of literature. A publication was considered relevant if it addressed S(E)NA as well as EG.

\subsubsection{Calculation of the similarity network measures}

After importing the similarity matrix into Gephi, we calculated the degree centrality for each document. The degree centrality equals the number of documents with which a document shares a similarity link (Table 1 ). We detected modules using the modularity optimization algorithm for undirected networks (Blondel et al., 2008) with a resolution setting of 1.0.

\subsubsection{Identification of the topic categories}

Modules in the similarity network are clusters of documents that share more similarity with each other than with documents in other clusters. To label the modules in a meaningful way, we explored which topic was mainly addressed. The clustering of documents, however, might be influenced by different topic categories which exist in parallel. To extract these topic categories, we took the whole collection of documents and summed up the frequency values of each word across all documents. We discarded those words that occurred less than three times in the whole collection of documents. We manually perused this list and heuristically 
defined three different categories of topics: (1) the resources at stake and their uses or threats, (2) governance types, measures, and outcomes, and (3) the spatial reference or level of the study. The topic categories each consist of a list of words assigned to it. All the words that are not part of a topic category list are disregarded in the further topic detection analysis. The list of words assigned to the categories "Resource," "Governance," and "Spatial reference" can be found in Table B of the supplemental material. ${ }^{8}$ We searched for word occurrences from each topic category list in each document. As a result, documents were represented by three attributes: one word list per topic category per document. For the remainder of the topic detection analysis, the topic categories were treated separately to distinguish the different levels of content we are interested in.

\subsubsection{Detection of topics per module and per topic category with the frequency ranking technique}

We developed a process in RapidMiner to detect topics per module and topic category, based on the assumption that frequently occurring words determine topics. We ranked the words in each document attribute by their frequency. We created new attributes for each document which only contained the first- and secondhighest ranking words per topic category. We took the attributes of all documents pertaining to a module and defined them as a bag of words for each module in each topic category. We took the bag of words of each module and counted word frequencies. We kept only those words that occurred at least 10 times. These highest ranking words are the most frequent words in a module and thus we considered these words as representing the main topics addressed in it.

\subsubsection{Visualization of the similarity network}

Citation and similarity networks are two different methodological approaches to a bibliometric analysis of literature and are used to answer different questions. Therefore, we did not explicitly strive for visual coherence between the two network visualizations (e.g., regarding their size, color, modules, etc.).

We visualized the similarity network structure using the "Force Atlas" algorithm in Gephi, with link weights (i.e., cosine similarity) influencing the attraction force between documents. A higher cosine similarity was interpreted as a stronger attraction. To each module, we assigned a different number and color. Each node we labeled with the number of the module it belongs to and colored it accordingly. Larger nodes indicate a higher degree. The thickness of links between documents is proportional to their cosine similarity. The links are colored after their nodes of origin; this means that links connecting nodes of different modules feature a mix of their modules' colors.

8 See file: Schwenke\&Holzkaemper_SENA in EG Tables B\&C_TopicCategory WordLists.pdf (Schwenke \& Holzkämper, 2020). 
We produced one visualization per topic category, labeled the modules according to the main topics they address, and sized the labels proportional to the word frequency. Accounting for distinct sub-clusters in each module, we labeled them with the locally frequent topics: We temporarily labeled single documents with their first- and second-ranked words and thereby could localize accumulations of words. We labeled sub-clusters when the locally accumulating word was among the 10 highest ranking words for the whole module.

\subsubsection{Detection of topics with Latent Dirichlet Allocation (LDA)}

We used the Latent Dirichlet Allocation (LDA, see Blei et al., 2003) operator in RapidMiner as a parallel method to detect topics in each topic category of the similarity network. Including a second, parallel method gave us the opportunity to complement the topic detection and to corroborate the results found by both methods. LDA is an automated method to identify topics in documents. The method assumes that there are multiple topics addressed in a collection of publications and that each publication can reveal characteristics of several topics. LDA identifies topics by word co-occurrences across publication models. It defines a topic by words that occur frequently across the same set of publication models. LDA then allocates words of the publication model collection to topics and weighs the words by how often they occur in the topic. Each topic is then modeled by a list of descriptive words with their respective weights. LDA might allocate words so that they describe several topics, but with different weights. Topics are modeled by a topic word list. Publications are modeled by a publication word list. By comparing topic word lists with publication word lists, LDA is able to measure the relative influence each topic has on each document. LDA assigns a value between 0 and 1 to each topic, with 0 indicating no influence of the topic model on the publication model and 1 indicating that the publication model is entirely influenced by the respective topic model. This value indicates the topic by which a publication can be best assigned, thus called confidence value.

Typically, LDA is applied to detect topics of single documents in a collection of documents. Our intention, however, was to detect topics for modules and not for single documents. For our use of the LDA operator, a topic category thus equaled a collection of documents, while each module equaled a document. We set the "number of topics" parameter according to the number of modules identified with the modularity optimization algorithm in Gephi. We used alpha and beta heuristics and the setting "optimize hyperparameters." From the topic word lists identified

9 Alpha and beta are hyperparameters that define how much either a document is allowed to be associated with more than one topic or a word is allowed to be associated with more than one topic. Alpha influences the number of topics per document, while beta influences the number of words per topic. In practice, a high alpha value will lead to documents being more similar in terms of what topics they contain. A high beta value will similarly lead to topics being more similar in terms of the words they contain. RapidMiner gives the option to optimize the hyperparameters alpha and beta during every iteration. This means that documents are likely to contain a mixture of most of the topics, but could also display a specific topic distribution. 
with LDA, we kept those words that occurred at least 10 times to describe a topic. A complete list of the topics identified by LDA and the five highest weighted words can be found in Table $\mathrm{C}$ of the supplemental material. ${ }^{10}$ Table $6(\mathrm{~A}-\mathrm{C})$ in the Results section shows the confidence value tables, indicating the allocation of topics across each module and of modules across each topic. The values indicate the confidence by which a module is influenced by a certain topic. The values also indicate to which module a topic can be best assigned.

\section{Results}

Between the vast amount of literature from the field of EG ( $>69,000$ articles) and the considerable amount of S(E)NA literature ( $>5,000$ articles), there is an intersection of 241 articles (Figure 2). The list of all 241 publications and their topics is provided in Table D of the supplemental material. ${ }^{11}$ Figure 2 indicates that although this intersection is still proportionally very small compared to the EG and S(E)NA fields ( 0.3 percent and 4.7 percent respectively), there is a continuous increase of articles that apply or discuss the application of S(E)NA in EG contexts in the last decade (Figure 3).

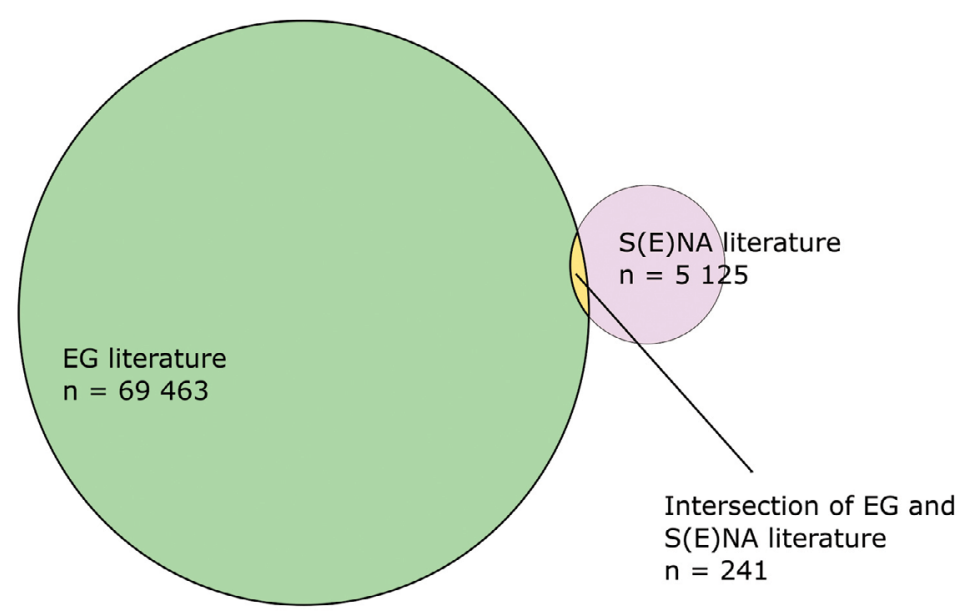

Figure 2. Schematic representation of the bodies of scientific literature addressing (A) EG (green), (B) S(E)NA (violet), and (C) their intersection (yellow).

Note: The size of circles and their intersection is proportional to the absolute number of articles $(n)$ attributed to the different bodies of literature.

Source: Authors' summary. Data were collected on January 22, 2019, using the Web of Science database (ISI Thomson Reuters) and includes literature from the earliest record until the end of 2018.

10 See file: Schwenke\&Holzkaemper_SENA in EG Tables B\&C_TopicCategory WordLists.pdf (Schwenke \& Holzkämper, 2020).

11 See file: Schwenke\&Holzkaemper_SENA in EG Table D_PublicationList.csv (Schwenke \& Holzkämper, 2020). 


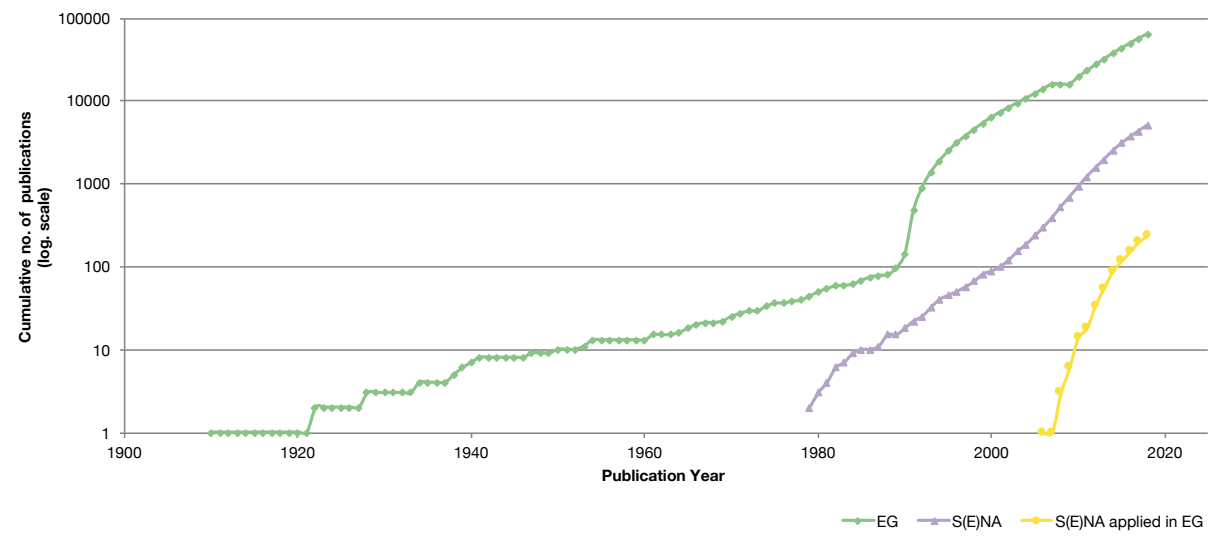

Figure 3. Development of scientific literature addressing EG, S(E)NA, and both research fields in combination.

Source: Authors' summary. Data were collected on January 22, 2019, using the Web of Science database (ISI Thomson Reuters).

\subsection{Descriptive statistics for the citation and similarity networks}

The citation network comprises 241 nodes (= publications); of these, 122 are isolates and 15 form small components (dyads and triads) not connected with the main network component. The main component consists of 104 articles which are connected by 173 citation links (Table 2).

The similarity network comprises the same 241 nodes, but it greatly differs from the citation network in the composition of links. The procedure to reduce density by applying a threshold of 10 percent cosine similarity cut off 16 articles from the network, which then became isolates (Table 3). From these publications, 7 were not related to the application of $S(E) N A$ in EG, while 9 were assessed as relevant, among them highly relevant publications such as Scott (2015) and Schoon et al. (2017).

Table 2. Network metrics for the citation and similarity networks from scientific literature applying S(E)NA in EG.

\begin{tabular}{|l|c|c|}
\hline Network metrics & Citation network & Similarity network \\
\hline Total no. of publications & 241 & 241 \\
\hline No. of isolates or small components & 137 & 16 \\
\hline Network metrics of main component & \multicolumn{2}{|l|}{} \\
\hline No. of publication nodes & 104 & 225 \\
\hline No. of links & 173 & 1,904 \\
\hline Density & 0.013 & 0.038 \\
\hline Max. Authority score & 0.49 & - \\
\hline
\end{tabular}


Network metrics

Citation network

Similarity network

\begin{tabular}{|l|c|c|}
\hline Max. Hub score & 0.31 & - \\
\hline Max degree & 13 & 60 \\
\hline Max. betweenness centrality & 24.83 & 1,526 \\
\hline No. of modules & 9 & 9 \\
\hline
\end{tabular}

Note: $\mathrm{S}(\mathrm{E}) \mathrm{NA}$ = social (-ecological) network analysis; $\mathrm{EG}=$ environmental governance.

Source: Authors' summary. Data were collected on January 22, 2019, using the Web of Science database (ISI Thomson Reuters).

Table 3. Isolates of the similarity network of scientific literature applying S(E)NA in EG, and their contents.

\begin{tabular}{|c|c|c|}
\hline Isolated article & Content & Relevant? \\
\hline Alexander (2012) & $\begin{array}{l}\text { Brownfield remediation and redevelopment projects as } \\
\text { social networks }\end{array}$ & yes \\
\hline Chen et al. (2018) & Sustainable resource flows in entrepreneurial networks & yes \\
\hline Holmes et al. (2017) & $\begin{array}{l}\text { Supportive networks for threatened bird species } \\
\text { conservation }\end{array}$ & yes \\
\hline Kreakie et al. (2016) & Conservation alliance network & yes \\
\hline Le et al. (2018) & $\begin{array}{l}\text { Stakeholder networks of sustainable waste } \\
\text { management }\end{array}$ & yes \\
\hline Ngaruiya (2015) & $\begin{array}{l}\text { Application of SNA to analyze medicinal plant } \\
\text { conservation governance }\end{array}$ & yes \\
\hline Ramirez et al. (2018) & $\begin{array}{l}\text { Use of SNA to explain inclusion of small agri-food } \\
\text { producers }\end{array}$ & yes \\
\hline Scott (2015) & SNA application in environmental governance & yes \\
\hline Schoon et al. (2017) & EG networks & yes \\
\hline Datta et al. (2012) & IBM's jazz initiative & no \\
\hline Fazekas \& Toth (2016) & State capture and corruption & no \\
\hline Gluckler \& Ries (2012) & Philanthropy & no \\
\hline $\begin{array}{l}\text { Ireni-Saban \& } \\
\text { Borohowitch (2017) }\end{array}$ & Embryonic stem cell research & no \\
\hline Kinsella (2014) & Small arms illegal trade & no \\
\hline Sciarini (2014) & Swiss consensus democracy & no \\
\hline Sohn \& Giffinger (2015) & Cross-border metropolitan governance & no \\
\hline
\end{tabular}

Note: $S(E) N A$ = social (-ecological) network analysis; $E G$ = environmental governance.

Source: Authors' summary. Data were collected on January 22, 2019, using the Web of Science database (ISI Thomson Reuters). Complete references can be found in the supplemental material. ${ }^{12}$

12 See file: Schwenke\&Holzkaemper_SENA in EG Table D_PublicationList.csv (Schwenke \& Holzkämper, 2020). 


\subsection{Citation network}

Figure $4(\mathrm{~A}-\mathrm{C})$ shows network visualizations of the main components of the citation network of literature applying S(E)NA in EG. (A) highlights sources (authority), (B) highlights storers (hub), and (C) highlights bridges (betweenness centrality) of knowledge. In total, we identified 20 of 241 publications with central positions as either sources, storers, or bridges of knowledge in the citation network. Of these 20 central publications, two stand out in terms of several of our measures. The content analysis of the 20 most central publications showed that eight feature "management/planning/policy," seven feature water related topics ("water," "river," "coastal," "marine") and six feature "collaboration." For further discussion, we included those publications that showed noticeably higher values than the other references: the eight publications with the highest HITS values (authorities and hubs), and the seven publications with the highest betweenness centralities (Table 4). Nearly all publications that occupy bridging positions (six of these seven) mention "collaboration" in their titles. "Collaboration" is not mentioned in the titles of the publications that rank highly in authority and hub values.

The most prominent structural roles in the citation network are occupied by Fliervoet et al. (2016) and Mills et al. (2014). These publications attain high values in betweenness centrality and authority (Mills et al., 2014), or in all three of the calculated measures (Fliervoet et al., 2016). The publication by Mills et al. (2014) occupies a relatively central hub position within the citation network as well (hub score $=0.14$ ), even though it is not among the highest ranking hubs. In their publication, Mills et al. (2014) explain three potential contributions SNA has to offer to conservation planning: (1) identifying stakeholders and their roles, (2) purposefully creating and facilitating links, and (3) prioritizing conservation action by using social connectivity along with ecological data. They describe SNA as a valuable tool for conservation, which supports decision-making, copes with challenges, and is useful to design future research actions.

Fliervoet et al. (2016) is among the publications ranking highest in terms of authority, hub, and betweenness centrality values. This publication gives a detailed description of relevant network metrics and a comprehensive overview of the theories behind natural resource governance. Furthermore, Fliervoet et al. (2016) explain the consequences of removing central actors from natural resource governance networks.

Most nodes that occupy structurally important positions in the citation network are associated to the Modules 5 (light green) and 6 (violet). Module 5 encompasses two (of eight) of all authorities, three (of eight) of all hubs, and two (of seven) of all publications with a high betweenness centrality. Module 6 assembles three (of eight) of all authorities, four (of eight) of all hubs and two (of seven) of all publications with a high betweenness centrality. In Table 5, we list the ten publications cited most often by the 241 publications applying SNA in EG, including the number of 
times they have been cited. Six of these ten publications are about theories, methods and tools for the analysis of social networks (Wasserman \& Faust, 1994; Borgatti et al., 2002; Freeman, 1978; Granovetter, 1973; Hanneman \& Riddle, 2005; Scott, 2000), one deals with governance theory (Ostrom, 1990), and three publications address the central topic of this article: the application of S(E)NA in EG (Bodin \& Crona, 2009; Prell et al., 2009; Folke et al., 2005).

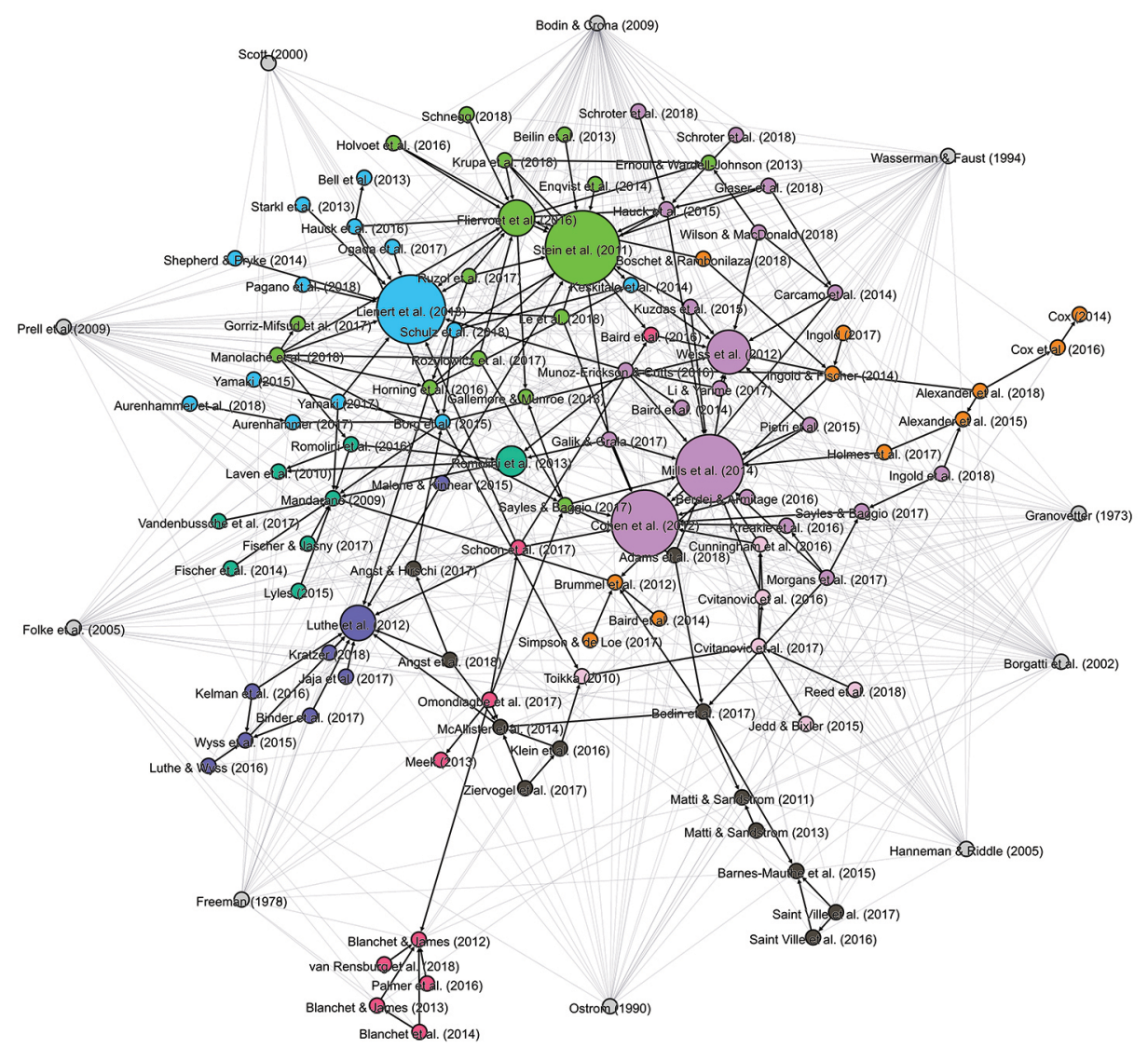

Figure 4A. Citation network of the scientific literature applying S(E)NA in EG: sources (authority score, $n=8$ ).

Note: Figure 4 (A-C). Citation network of the scientific literature applying S(E)NA in EG. Includes the 10 most-cited references (light gray) that are cited but are not among the results of the literature search; thus they are not considered parts of the citation network. Node color indicates modules, calculated using Gephi (Bastian et al., 2009). The highest ranking publications, regarding their influence as (A) sources (authority score, $n=8$ ), (B) storers (hub score, $n=8$ ), and (C) bridges (betweenness centrality, $n=7$ ) of knowledge, are sized according to their values. All other nodes are visualized by a minimum size.

Source: Authors' summary. Data were collected on January 22, 2019, using the Web of Science database (ISI Thomson Reuters). 


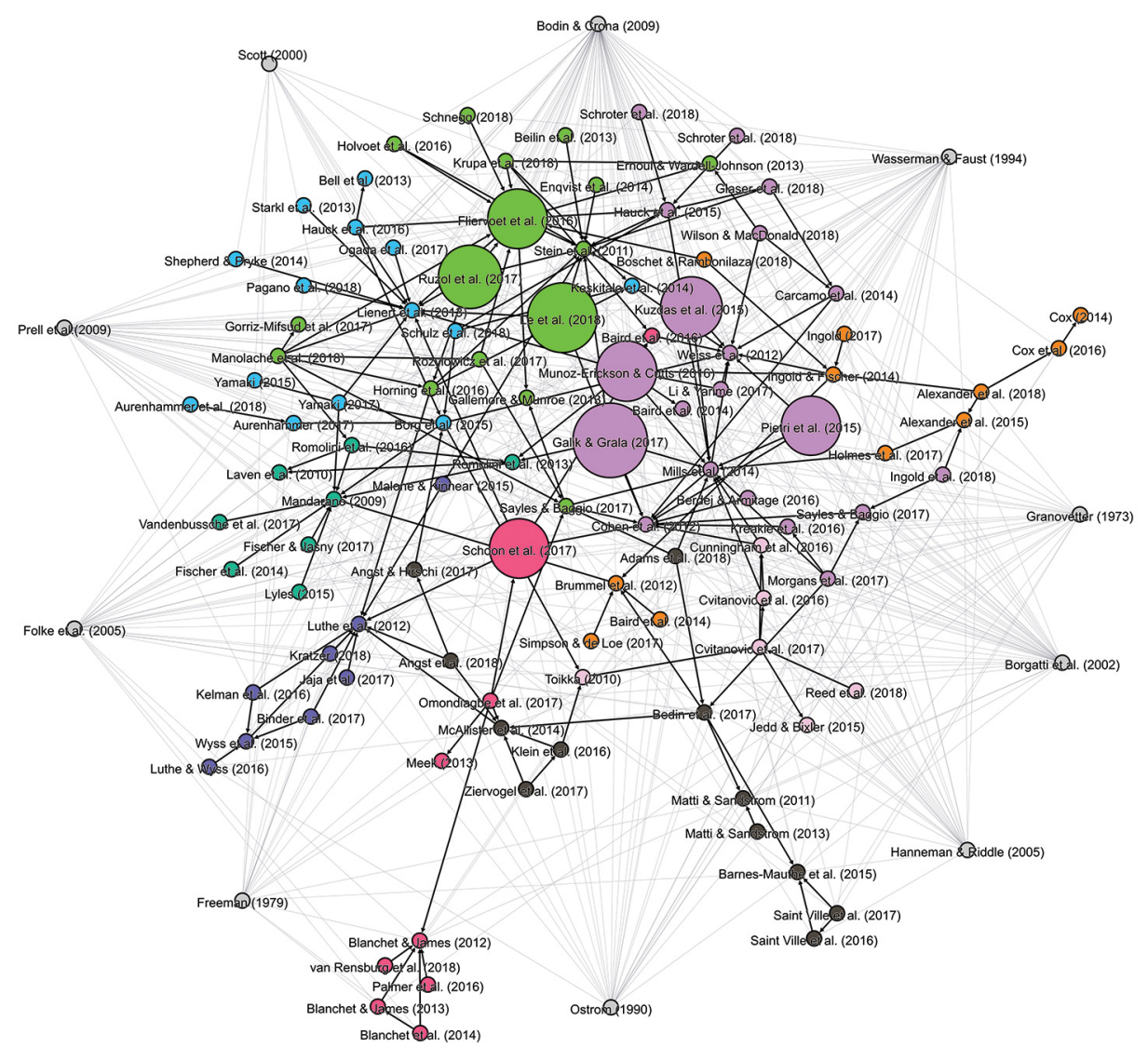

Figure 4B. Citation network of the scientific literature applying S(E)NA in EG: storers (hub score, $\boldsymbol{n}=\mathbf{8}$ ).

Note: Figure $4(\mathrm{~A}-\mathrm{C})$. Citation network of the scientific literature applying S(E)NA in EG. Includes the 10 most-cited references (light gray) that are cited but are not among the results of the literature search; thus they are not considered parts of the citation network. Node color indicates modules, calculated using Gephi (Bastian et al., 2009). The highest ranking publications, regarding their influence as (A) sources (authority score, $n=8$ ), (B) storers (hub score, $n=8$ ), and (C) bridges (betweenness centrality, $n=7$ ) of knowledge, are sized according to their values. All other nodes are visualized by a minimum size.

Source: Authors' summary. Data were collected on January 22, 2019, using the Web of Science database (ISI Thomson Reuters). 


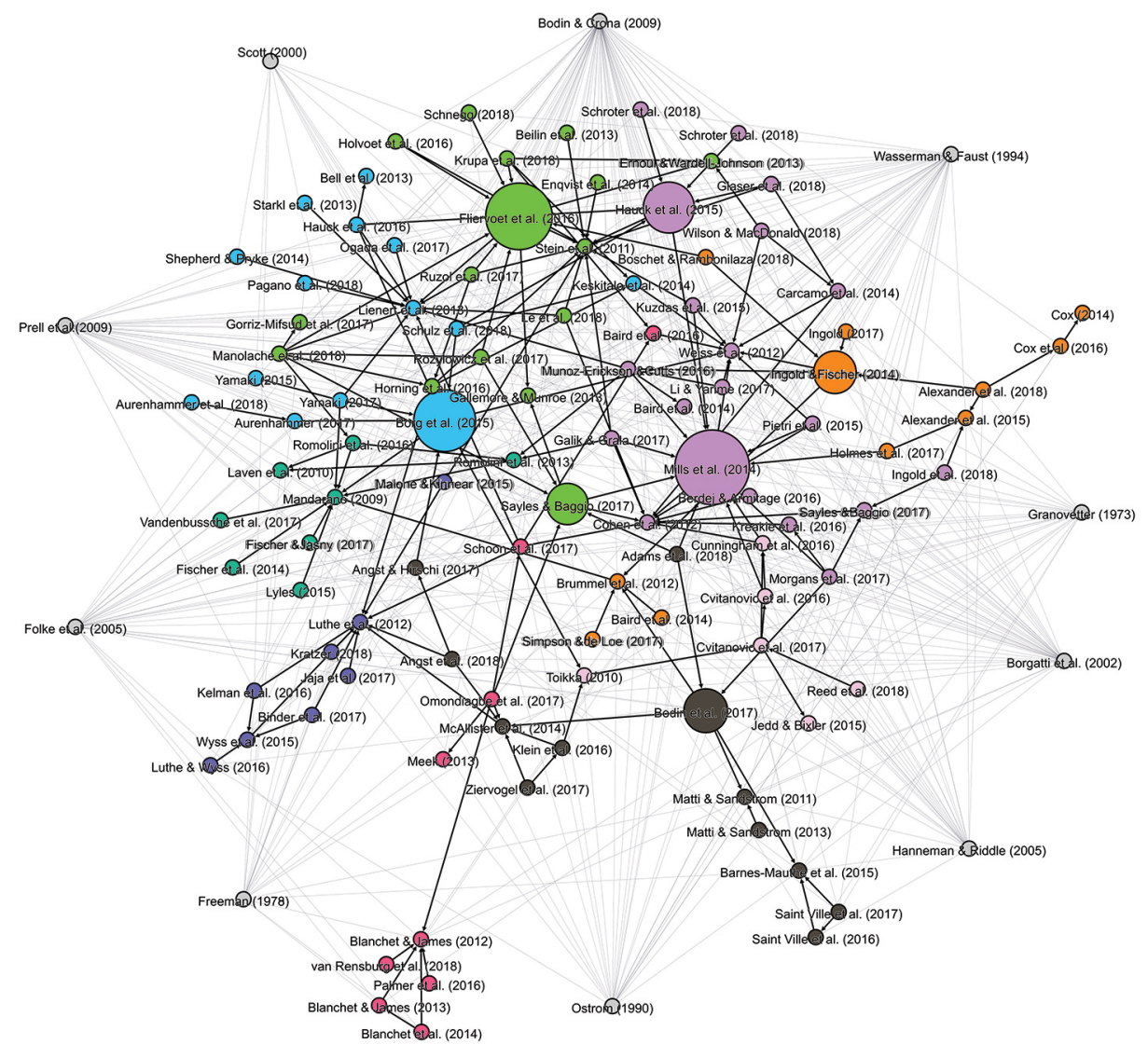

Figure 4C. Citation network of the scientific literature applying S(E)NA in EG: bridges (betweenness centrality, $n=7$ ).

Note: Figure $4(\mathrm{~A}-\mathrm{C})$. Citation network of the scientific literature applying S(E)NA in EG. Includes the 10 most-cited references (light gray) that are cited but are not among the results of the literature search; thus they are not considered parts of the citation network. Node color indicates modules, calculated using Gephi (Bastian et al., 2009). The highest ranking publications, regarding their influence as (A) sources (authority score, $n=8$ ), (B) storers (hub score, $n=8$ ), and (C) bridges (betweenness centrality, $n=7$ ) of knowledge, are sized according to their values. All other nodes are visualized by a minimum size.

Source: Authors' summary. Data were collected on January 22, 2019, using the Web of Science database (ISI Thomson Reuters). 
Table 4. Publications representing authorities, hubs, and bridges (betweenness centrality; BC) of knowledge in the citation network of scientific literature applying $S(E) N A$ in $E G$.

\begin{tabular}{|c|c|c|c|c|}
\hline Author (year) & Title & BC & Authority & Hub \\
\hline $\begin{array}{l}\text { Bodin et al. } \\
(2017)\end{array}$ & $\begin{array}{l}\text { Collaborative Networks for Effective Ecosystem- } \\
\text { Based Management: A Set of Working Hypotheses }\end{array}$ & 12.00 & 0.05 & 0.01 \\
\hline $\begin{array}{l}\text { Borg et al. } \\
(2015)\end{array}$ & $\begin{array}{l}\text { Social Capital and Governance: A Social Network } \\
\text { Analysis of Forest Biodiversity Collaboration in } \\
\text { Central Finland }\end{array}$ & 19.50 & 0.07 & 0.07 \\
\hline $\begin{array}{l}\text { Cohen et al. } \\
(2012)\end{array}$ & $\begin{array}{l}\text { Social Networks Supporting Governance of Coastal } \\
\text { Ecosystems in Solomon Islands }\end{array}$ & 0.00 & 0.42 & 0.00 \\
\hline $\begin{array}{l}\text { Fliervoet et al. } \\
(2016)\end{array}$ & $\begin{array}{l}\text { Analyzing Collaborative Governance Through } \\
\text { Social Network Analysis: A Case Study of } \\
\text { River Management Along the Waal River in } \\
\text { The Netherlands }\end{array}$ & 21.50 & 0.17 & 0.23 \\
\hline $\begin{array}{l}\text { Galik \& Grala } \\
(2017)\end{array}$ & $\begin{array}{l}\text { Conservation Program Delivery in the Southern US: } \\
\text { Preferences and Interactions }\end{array}$ & 0.00 & 0.00 & 0.31 \\
\hline $\begin{array}{l}\text { Hauck et al. } \\
(2015)\end{array}$ & $\begin{array}{l}\text { Seeing the Forest and the Trees: Facilitating } \\
\text { Participatory Network Planning in Environmental } \\
\text { Governance }\end{array}$ & 15.00 & 0.07 & 0.19 \\
\hline $\begin{array}{l}\text { Ingold \& } \\
\text { Fischer (2014) }\end{array}$ & $\begin{array}{l}\text { Drivers of Collaboration to Mitigate Climate Change: } \\
\text { An Illustration of Swiss Climate Policy over } 15 \text { Years }\end{array}$ & 11.50 & 0.07 & .05 \\
\hline $\begin{array}{l}\text { Kuzdas et al. } \\
(2015)\end{array}$ & $\begin{array}{l}\text { Integrated and Participatory Analysis of Water } \\
\text { Governance Regimes: The Case of the Costa Rican } \\
\text { Dry Tropics }\end{array}$ & 0.00 & 0.00 & 0.24 \\
\hline Le et al. (2018) & $\begin{array}{l}\text { Understanding the Stakeholders' Involvement } \\
\text { in Utilizing Municipal Solid Waste in Agriculture } \\
\text { through Composting: A Case Study of Hanoi, } \\
\text { Vietnam }\end{array}$ & 0.00 & 0.00 & 0.29 \\
\hline $\begin{array}{l}\text { Lienert et al. } \\
(2013)\end{array}$ & $\begin{array}{l}\text { Stakeholder Analysis Combined with Social } \\
\text { Network Analysis Provides Fine-grained Insights } \\
\text { into Water Infrastructure Planning Processes }\end{array}$ & 0.00 & 0.44 & 0.00 \\
\hline $\begin{array}{l}\text { Luthe et al. } \\
\text { (2012) }\end{array}$ & $\begin{array}{l}\text { Network Governance and Regional Resilience to } \\
\text { Climate Change: Empirical Evidence from Mountain } \\
\text { Tourism Communities in the Swiss Gotthard Region }\end{array}$ & 0.00 & 0.17 & 0.00 \\
\hline $\begin{array}{l}\text { Mills et al. } \\
(2014)\end{array}$ & $\begin{array}{l}\text { Linking Regional Planning and Local Action: } \\
\text { Towards Using Social Network Analysis in } \\
\text { Systematic Conservation Planning }\end{array}$ & 24.83 & 0.43 & 0.14 \\
\hline $\begin{array}{l}\text { Muñoz- } \\
\text { Erickson \& } \\
\text { Cutts (2016) }\end{array}$ & $\begin{array}{l}\text { Structural Dimensions of Knowledge-Action } \\
\text { Networks for Sustainability }\end{array}$ & 9.00 & 0.01 & 0.24 \\
\hline $\begin{array}{l}\text { Pietri et al. } \\
(2015)\end{array}$ & $\begin{array}{l}\text { The Coral Triangle Initiative and Regional } \\
\text { Exchanges: Strengthening Capacity through } \\
\text { a Regional Learning Network }\end{array}$ & 0.00 & 0.00 & 0.23 \\
\hline $\begin{array}{l}\text { Romolini et al. } \\
\text { (2013) }\end{array}$ & $\begin{array}{l}\text { Assessing and Comparing Relationships between } \\
\text { Urban Environmental Stewardship Networks and } \\
\text { Land Cover in Baltimore and Seattle }\end{array}$ & 6.00 & 0.13 & 0.02 \\
\hline $\begin{array}{l}\text { Ruzol et al. } \\
\text { (2017) }\end{array}$ & $\begin{array}{l}\text { Understanding Water Pollution Management: } \\
\text { Evidence and Insights from Incorporating Cultural } \\
\text { Theory in Social Network Analysis }\end{array}$ & 0.00 & 0.00 & 0.25 \\
\hline
\end{tabular}


Author (year) Title

\begin{tabular}{|l|l|c|c|c|}
\hline $\begin{array}{l}\text { Sayles \& } \\
\text { Baggio (2017) }\end{array}$ & $\begin{array}{l}\text { Who Collaborates and Why: Assessment and } \\
\text { Diagnostic of Governance Network Integration for } \\
\text { Salmon Restoration in Puget Sound, USA }\end{array}$ & 11.00 & 0.08 & 0.20 \\
\hline $\begin{array}{l}\text { Schoon et al. } \\
(2017)\end{array}$ & $\begin{array}{l}\text { The Emergence of an Environmental Governance } \\
\text { Network: The Case of the Arizona Borderlands }\end{array}$ & 3.50 & 0.01 & 0.23 \\
\hline $\begin{array}{l}\text { Stein et al. } \\
(2011)\end{array}$ & $\begin{array}{l}\text { A Social Network Approach to Analyzing Water } \\
\text { Governance: The Case of the Mkindo Catchment, } \\
\text { Tanzania }\end{array}$ & 0.00 & 0.49 & 0.00 \\
\hline $\begin{array}{l}\text { Weiss et al. } \\
(2012)\end{array}$ & $\begin{array}{l}\text { Knowledge Exchange and Policy Influence in } \\
\text { a Marine Resource Governance Network }\end{array}$ & 0.00 & 0.24 & 0.00 \\
\hline
\end{tabular}

Note: As shown in the network representation in Figure 4. Gray shaded boxes indicate top ranked values. Publications are highlighted by shades of gray and thick lines when they are among the highest ranking articles in more than one of the three measures. $\mathrm{BC}=$ betweenness centrality; $\mathrm{S}(\mathrm{E}) \mathrm{NA}=$ social (-ecological) network analysis; $E G$ = environmental governance.

Source: Authors' summary. Data were collected on January 22, 2019, using the Web of Science database (ISI Thomson Reuters). Complete references can be found in the supplemental material. ${ }^{13}$

Table 5. Ten publications cited most often by the main cluster of the citation network emerging between scientific literature applying $S(E) N A$ in $E G$. The publications we list are cited by but are not part of the citation network under consideration.

\begin{tabular}{|c|c|c|}
\hline Author (year) & Title & In-degree \\
\hline $\begin{array}{l}\text { Wasserman \& Faust } \\
\text { (1994) }\end{array}$ & Social Network Analysis: Methods and Applications & 100 \\
\hline Bodin \& Crona (2009) & $\begin{array}{l}\text { The Role of Social Networks in Natural Resource } \\
\text { Governance: What Relational Patterns make a Difference? }\end{array}$ & 98 \\
\hline Borgatti et al. (2002) & $\begin{array}{l}\text { UCINET for Windows: Software for Social Network } \\
\text { Analysis }\end{array}$ & 78 \\
\hline Freeman (1978) & Centrality in Social Networks Conceptual Clarification & 55 \\
\hline Prell et al. (2009) & $\begin{array}{l}\text { Stakeholder Analysis and Social Network Analysis in } \\
\text { Natural Resource Management }\end{array}$ & 52 \\
\hline Folke et al. (2005) & Adaptive Governance of Social-ecological Systems & 51 \\
\hline Granovetter (1973) & The Strength of Weak Ties & 50 \\
\hline $\begin{array}{l}\text { Hanneman \& Riddle } \\
(2005)\end{array}$ & Introduction to Social Network Methods & 44 \\
\hline Ostrom (1990) & $\begin{array}{l}\text { Governing the Commons: The Evolution of Institutions for } \\
\text { Collective Action }\end{array}$ & 43 \\
\hline Scott (2000) & Social Network Analysis: A Handbook & 33 \\
\hline
\end{tabular}

Note: $\mathrm{S}(\mathrm{E}) \mathrm{NA}=$ social (-ecological) network analysis; $\mathrm{EG}=$ environmental governance.

Source: Authors' summary.

13 See file: Schwenke\&Holzkaemper_SENA in EG Table D_PublicationList.csv (Schwenke \& Holzkämper, 2020). 


\subsection{Similarity network}

Figure 5 (A-C) shows network visualizations of the main component of the similarity network mapping the literature applying S(E)NA in EG and the topics addressed by its modules, as identified using the frequency ranking technique. Table 6 gives the topics as identified by the LDA technique, labeled with the first and second ranking words. Each figure and table is divided by topic category: (A) "Resources," (B) "Governance," and (C) "Spatial references." Using the frequency ranking technique, we could assign topics to eight of the modules in the "Resource" category, whereas we only found six topics in the "Governance" and the "Spatial reference" categories. In category (A) "Resources," the frequency ranking technique results in the topics "water," "climate," and "forest" for Modules 5, 6, and 0 respectively. Each of these modules features a distinct topic, identified by a very high occurrence of topics commonly addressed in the modules' publication models. In the "water" module, we also find a sub-cluster dealing with energy generation and in the "climate" module, there is a sub-cluster on tourism. Apart from the overarching distinct topic "climate," Module 6 also includes subtopics like "learning" and "capital." Modules 3, 8, 1, and 4 exhibit "ecosystem," "health," "fisheries," and "flood/disaster" as shared highest ranking publication topics respectively. However, these modules have less distinct topics. Both the "ecosystem" and "fisheries" modules also often feature the term "knowledge" ("fisheries" also "communication"). Module 7 differs from the other modules in that it does not represent a single influential topic, but several, less prominent topics. It is likewise influenced by the topics "food," "biodiversity," "innovation," "capacity," and "education." In the "Governance" category, the most distinct module is Module 1, which is mainly influenced by "collaboration" and "conservation." Several topics are repeated across modules: Module 5 is also assigned to the "collaboration" topic and Modules 0 and 7, and a sub-cluster of Module 6, are assigned to the topic "policy." Module 6 is strongly influenced by the topic "adaptation" (including a sub-cluster influenced by "resilience" and "change"). These topics occur only in Module 6. The category (C) "Spatial reference" is dominated by the topic "local," which is a shared publication topic across all modules. The "local" topic influences Modules 5, 1, and 6 to a high level, either exclusively (Module 5), or in combination with other spatial references (Module 1 "local/ marine" and Module 6 "local/ regional"). Both Modules 0 and 7 are separated into sub-clusters; they both feature the "local" topic toward the core of the network, and feature different topics toward the periphery of the network: "countries/national" (Module 0) and "international/ global" (Module 7). Module 3 distinguishes itself by a distinct "urban" topic, which is also unique for the whole network in this topic category. 


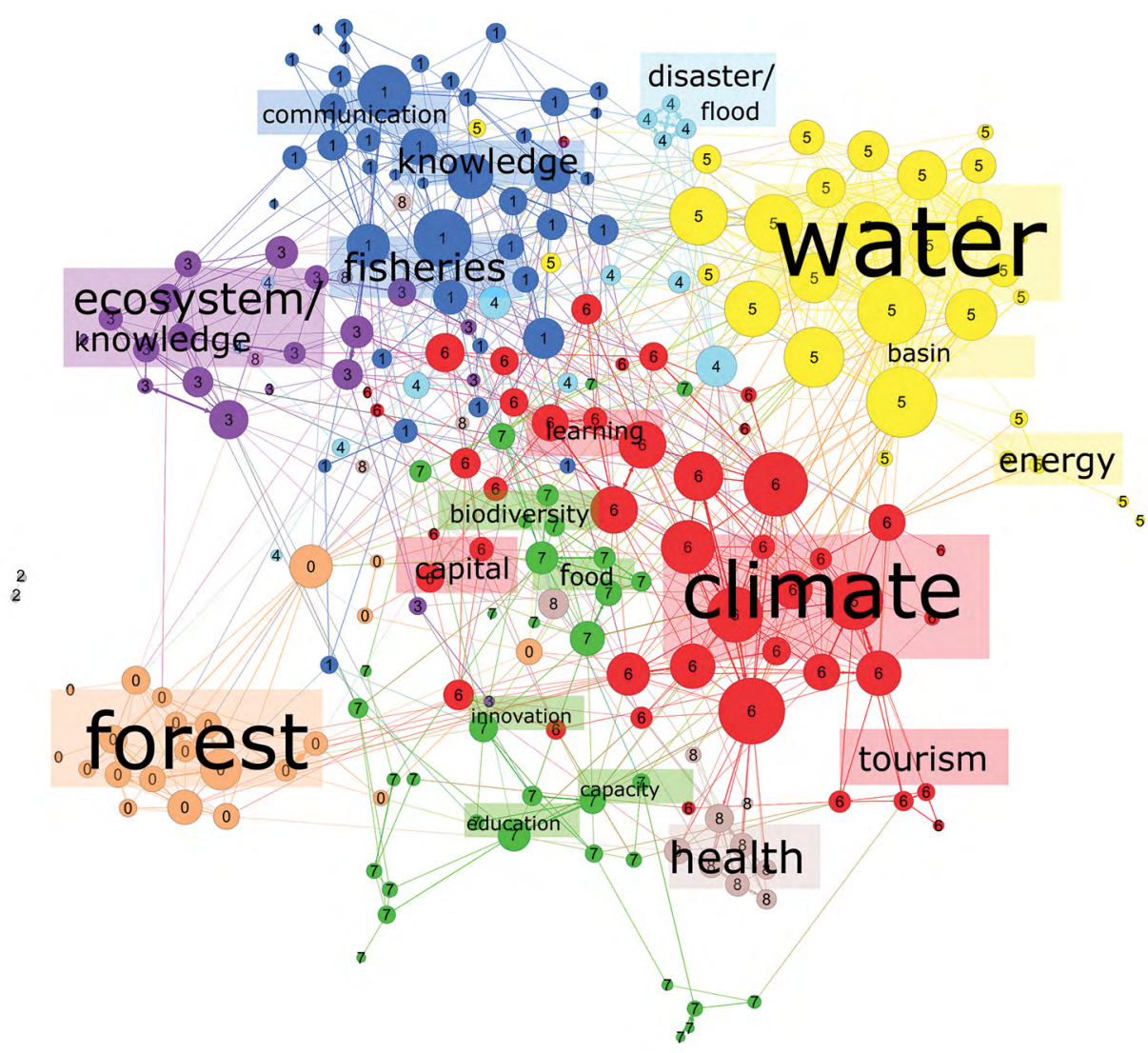

\section{Figure 5A. Similarity network for the category "Resources."}

Note: Figure 5(A-C). Similarity network for the category (A) "Resources," (B) "Governance," and (C) "Spatial reference" categories. Nodes are publication models: links indicate text similarity between publication models above a cosine similarity threshold of 0.1 . The thickness of links between publication models is proportional to their cosine similarity. Link color equals node color; links connecting two differently colored nodes display a mixed color. Nodes are sized after the degree measure, indicating the number of articles with which the node shares a similarity link. We numbered modules starting with 0. Module labels are sized according to word frequency.

Source: Authors' summary. Data were collected on January 22, 2019, using the Web of Science database (ISI Thomson Reuters). 


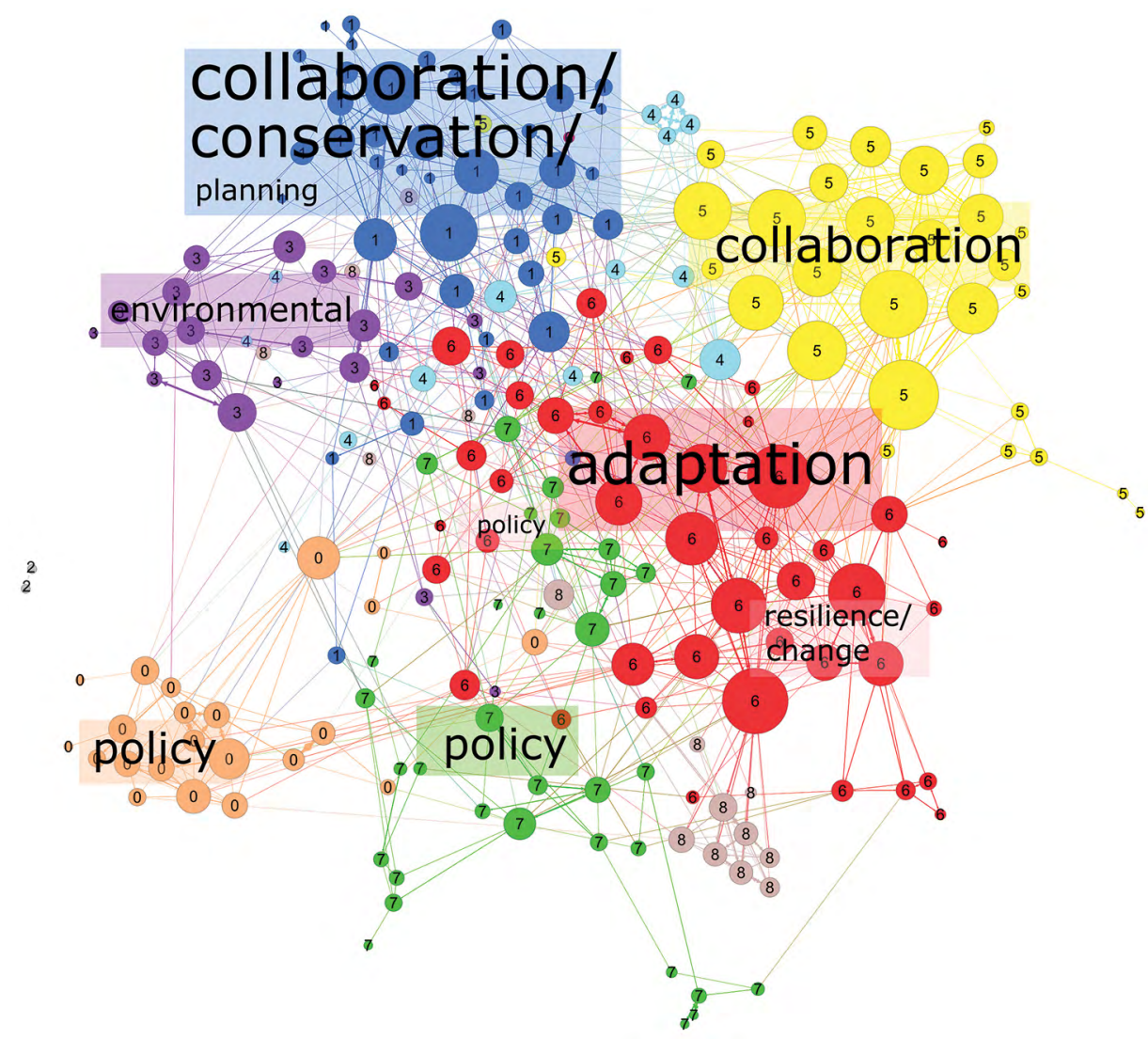

\section{Figure 5B. Similarity network for the category "Governance."}

Note: Figure 5(A-C). Similarity network for the category (A) "Resources," (B) "Governance," and (C) "Spatial reference" categories. Nodes are publication models: links indicate text similarity between publication models above a cosine similarity threshold of 0.1 . The thickness of links between publication models is proportional to their cosine similarity. Link color equals node color; links connecting two differently colored nodes display a mixed color. Nodes are sized after the degree measure, indicating the number of articles with which the node shares a similarity link. We numbered modules starting with 0. Module labels are sized according to word frequency.

Source: Authors' summary. Data were collected on January 22, 2019, using the Web of Science database (ISI Thomson Reuters).

We detected topics with the LDA method and found that in several cases, words that describe a LDA topic are similar to or match words that describe a topic after the frequency ranking technique. Table $6(\mathrm{~A}-\mathrm{C})$ shows the topics for each topic category, as detected by the LDA method (top) and the frequency ranking technique (left; numbers indicate the respective module to which the topic is assigned). We only considered words with weights of nine and higher as LDA topic descriptions - thus, rejected complete topics where the word weights of each topicdescribing word is below nine. Matches between the two methods, indicated by shared topic-describing words, are set in bold script. The brackets under the LDA topic give the number of the module(s) whose topic as identified by the frequency 
ranking technique matches the respective LDA topic by having one or more topicdescribing words in common. Values indicate the influence a topic has on the content of a module (confidence value), thereby visualizing the distribution of LDA topics across all modules. Darker colors were used to visualize highest confidence. Comparing values column-wise informs about the composition of a specific module by different LDA topics; comparing values per rows informs about the attribution of different modules to a specific LDA topic. Black boxes indicate that, for this module, the topic detected by the frequency ranking method coincides with the highest LDA confidence per topic. The total value under each topic indicates how much the complete topic category is influenced by the respective topic.

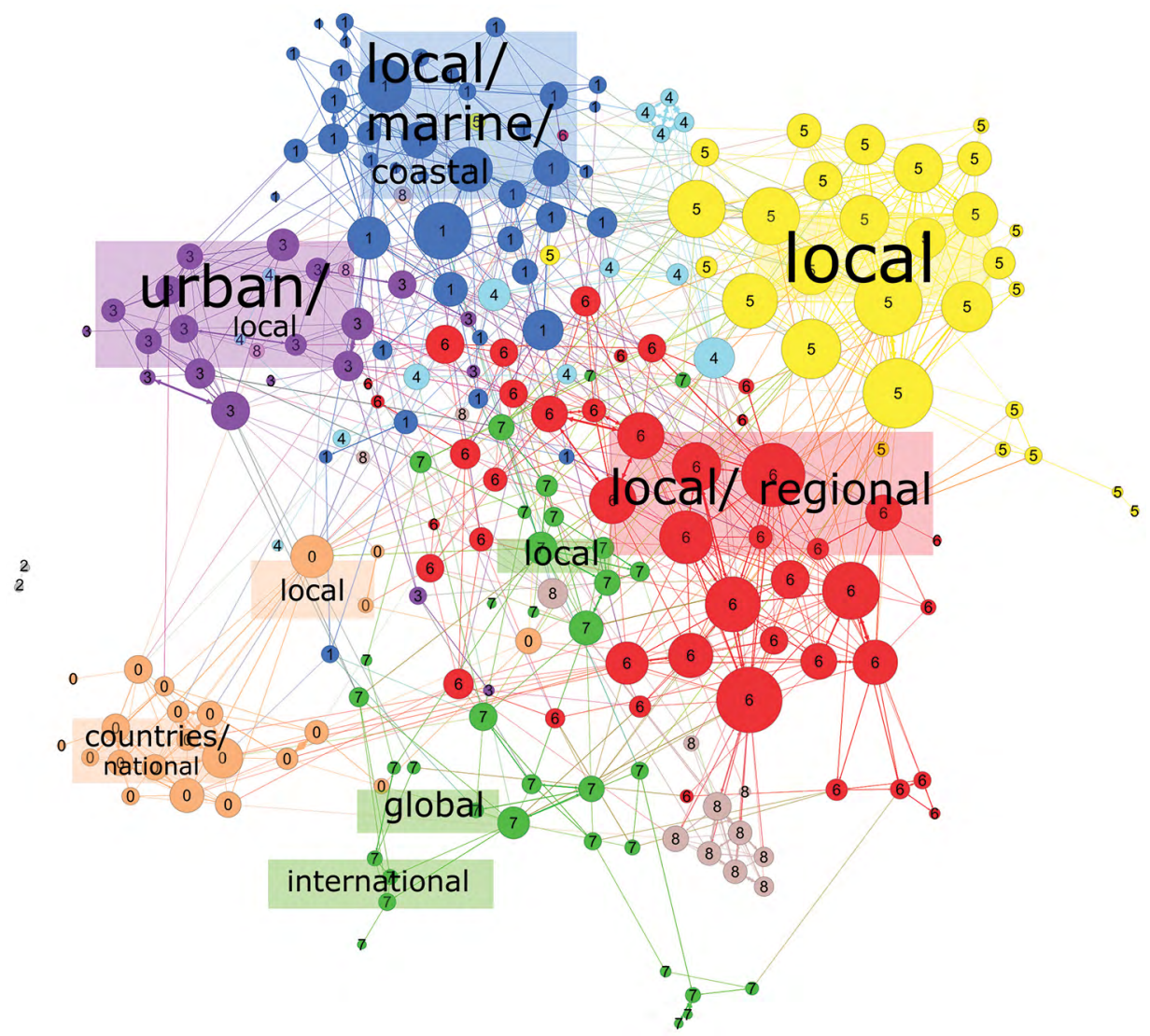

Figure 5C. Similarity network for the category "Spatial reference."

Note: Figure 5(A-C). Similarity network for the category (A) "Resources," (B) "Governance," and (C) "Spatial reference" categories. Nodes are publication models: links indicate text similarity between publication models above a cosine similarity threshold of 0.1 . The thickness of links between publication models is proportional to their cosine similarity. Link color equals node color; links connecting two differently colored nodes display a mixed color. Nodes are sized after the degree measure, indicating the number of articles with which the node shares a similarity link. We numbered modules starting with 0. Module labels are sized according to word frequency.

Source: Authors' summary. Data were collected on January 22, 2019, using the Web of Science database (ISI Thomson Reuters). 
The LDA technique detected nine topics in the "Resources" category, eight topics in the "Governance" category and seven in the "Spatial reference" category. In category (A) "Resources," LDA identified topics with a high resemblance to those identified with the frequency ranking technique (see Figure 5). LDA confirms the assignment of modules to topics detected with the frequency ranking technique in nearly all cases: Module 0 = "forest," 1 = "fisheries," 4 = "flood," 5 = "water, basin," 6 = "climate, capital," and 7 = "innovation, food." While Module 8 exhibits a high confidence score for the "health" topic, Module 7 turns out to be even more influenced by the "health" topic than Module 8. Considering the word matches, Module 3 indicates a good fit with the topic "knowledge, ecological, learning, fisheries, diversity," yet Module 6 ("climate") turns out to be more influenced by this topic than Module 3. Module 3, however, can be best attributed to the topic "information, influence, power, support, ecosystem." This also resonates with the attribution of Module 3 to the topic "ecological, knowledge" by the frequency ranking technique. It is noteworthy that the "information, influence, power, support, ecosystem" topic is prevalent with very high confidence values in all modules, reaching the highest total confidence value (3.234) for the category "Resources." In category (B) "Governance," one topic that LDA detects cannot be interpreted due to low word weights. The remaining eight topics resemble those detected with the frequency ranking method by having one or more topic-describing words in common (Figure 5). The confidence values for these topics indicate a good fit with the topic assignment by the frequency ranking method in three cases: Module 0 = "policy," 1 = "collaboration, conservation," and 6 = "change, adaptation." "Policy" is identified as a module-crossing theme with the frequency ranking method, and the frequency of "policy" as a shared topicdescribing word and the high confidence value of the topic "policy, environment, framework, government, development" across all modules agrees with this finding (total confidence value of 2.828). A similarly high confidence value across all modules can be found for the topic "stakeholder(s), collaborative, conservation, organization" (total value of 2.315). Topic analysis of the "Spatial reference" category reveals the importance of the topic "local" for all modules with both the ranking and the LDA method (total confidence value of 3.314), reaching its highest value in Module 6 ("climate"/"adaptation"). LDA also corroborates the assignment of the following modules: 1 = "coastal, marine," 3 = "urban," and 7 = "international." While the frequency ranking method detects the highest occurrence of shared attributes for Module 3 in the "Spatial reference" category, LDA detects the highest confidence value for Module 3 in the "Resources" category. 


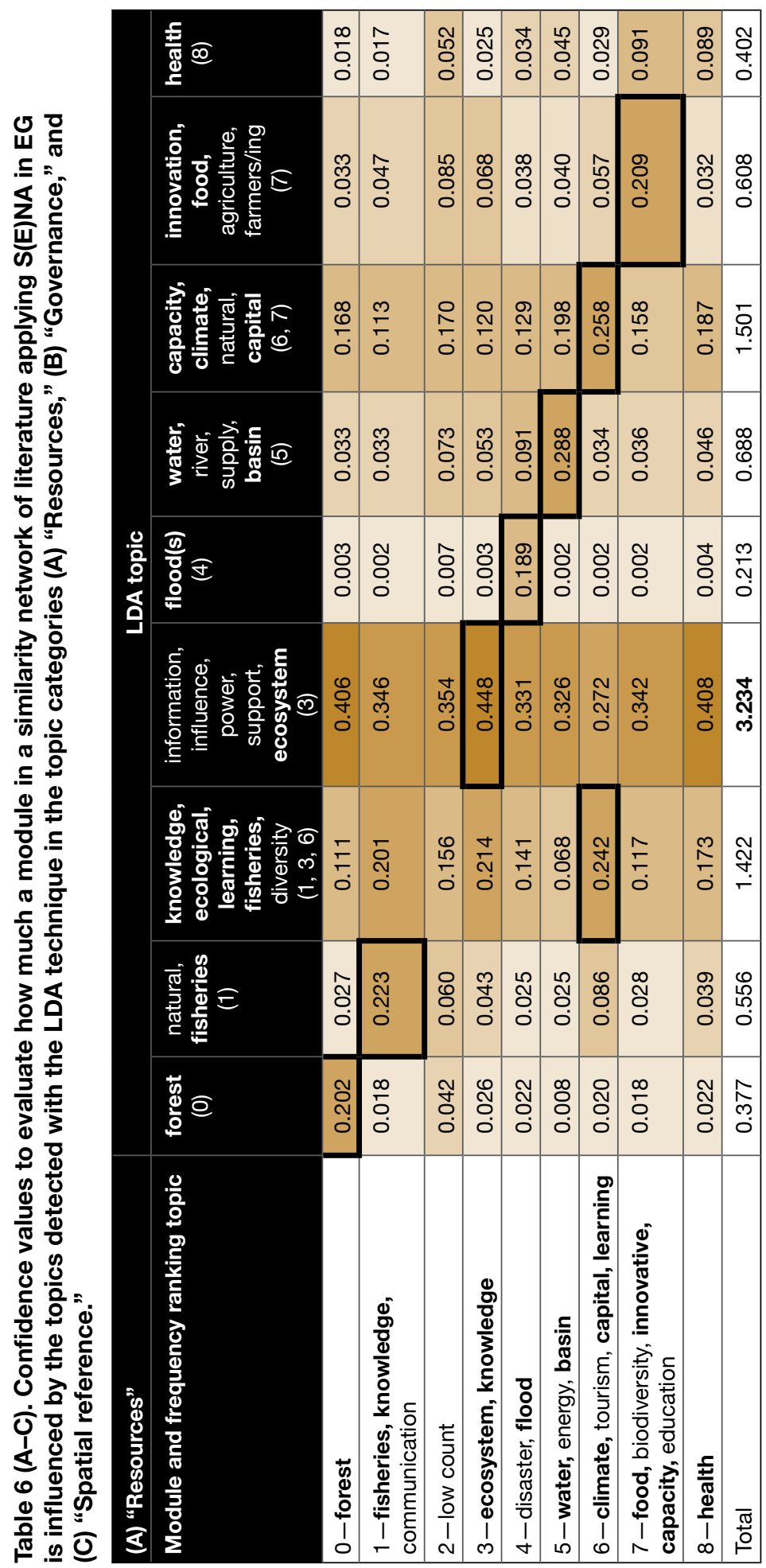




\begin{tabular}{|c|c|c|c|c|c|c|c|c|c|c|c|}
\hline & 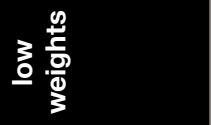 & $\begin{array}{l}10 \\
0 \\
0 \\
0\end{array}$ & $\begin{array}{l}\frac{1}{0} \\
0 \\
0\end{array}$ & $\begin{array}{l}\frac{\pi}{0} \\
0 \\
0\end{array}$ & $\begin{array}{l}0 \\
\stackrel{0}{0} \\
0\end{array}$ & $\begin{array}{l}\text { ஜ̊ } \\
0 \\
0\end{array}$ & $\begin{array}{l}\stackrel{\nabla}{\sigma} \\
\\
0\end{array}$ & 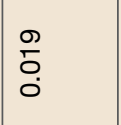 & \begin{tabular}{l}
$\ell$ \\
\hdashline \\
0
\end{tabular} & $\begin{array}{l}8 \\
\text { : } \\
0 \\
0\end{array}$ & 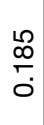 \\
\hline & 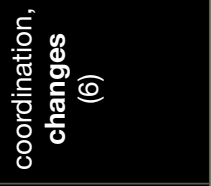 & $\frac{8}{\check{J}}$ & $\begin{array}{l}8 \\
8 \\
0 \\
0\end{array}$ & $\begin{array}{l}\text { ָे } \\
\text { ర్ }\end{array}$ & $\begin{array}{l}\tilde{N} \\
\tilde{O} \\
0\end{array}$ & $\begin{array}{l}\mathscr{P} \\
0 \\
0\end{array}$ & 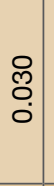 & $\begin{array}{l}\tilde{N} \\
\tilde{O} \\
0 \\
0\end{array}$ & $\begin{array}{l}0 \\
\stackrel{0}{0} \\
0 \\
0\end{array}$ & $\begin{array}{l}\text { Nి } \\
\text { Oे } \\
0\end{array}$ & $\begin{array}{l}\bar{\infty} \\
\text { m. } \\
0 \\
0\end{array}$ \\
\hline & 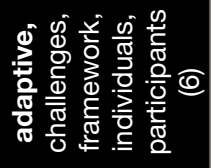 & $\begin{array}{l}0 \\
\tilde{O} \\
0 \\
0\end{array}$ & $\begin{array}{l}\text { 衣 } \\
\text { O } \\
0\end{array}$ & $\begin{array}{l}\text { ? } \\
\text { Oे } \\
\text { O }\end{array}$ & 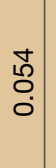 & $\begin{array}{l}0 \\
0 \\
0 \\
0\end{array}$ & \begin{tabular}{l}
$\ell$ \\
\hdashline \\
0 \\
0
\end{tabular} & 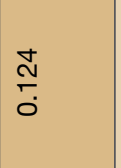 & $\begin{array}{l}\infty \\
\stackrel{\infty}{0} \\
0 \\
0\end{array}$ & $\begin{array}{l}0 \\
0 \\
0 \\
0 \\
0\end{array}$ & $\stackrel{1}{6}$ \\
\hline & 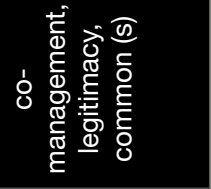 & $\begin{array}{l}\tilde{N} \\
\tilde{0} \\
0\end{array}$ & $\begin{array}{l}\stackrel{+}{\infty} \\
0 \\
0 \\
0\end{array}$ & $\begin{array}{l}\bar{m} \\
\text { ơ }\end{array}$ & 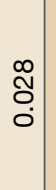 & 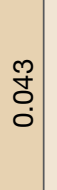 & 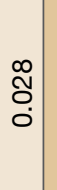 & \begin{tabular}{l}
00 \\
\hdashline \\
\hdashline \\
0
\end{tabular} & 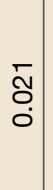 & $\begin{array}{l}\frac{12}{0} \\
0 \\
0 \\
0\end{array}$ & 孚 \\
\hline 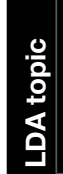 & 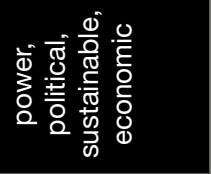 & $\mid \begin{array}{c}0 \\
\infty \\
\check{0} \\
0\end{array}$ & $\begin{array}{l}\text { Ñ} \\
\text { Oे } \\
0\end{array}$ & $\begin{array}{l}\frac{8}{\circ} \\
\text { 뭉 }\end{array}$ & $\begin{array}{c}\stackrel{\bar{N}}{\check{0}} \\
\stackrel{0}{n}\end{array}$ & $\frac{\bar{N}}{\sigma}$ & $\begin{array}{l}\bar{\sigma} \\
\\
\end{array}$ & 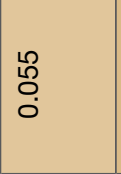 & 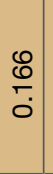 & $\begin{array}{l}\text { ठे } \\
8 \\
0\end{array}$ & 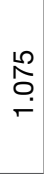 \\
\hline & 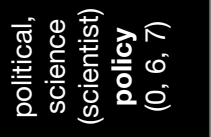 & $\begin{array}{l}\hat{8} \\
0 \\
0\end{array}$ & 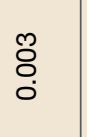 & $\begin{array}{l}\bar{\sigma} \\
\overline{0} \\
0\end{array}$ & $\begin{array}{l}\infty \\
\vdots \\
0 \\
0\end{array}$ & $\begin{array}{l}\bar{\sigma} \\
\dot{0}\end{array}$ & 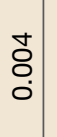 & 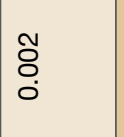 & $\begin{array}{l}\text { டூ } \\
0 \\
0\end{array}$ & $\begin{array}{l}\hat{8} \\
0 \\
0\end{array}$ & 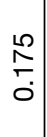 \\
\hline & 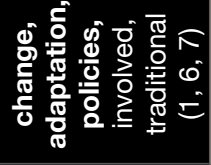 & $\begin{array}{l} \\
\infty \\
0 \\
0 \\
0\end{array}$ & 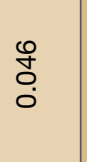 & $\frac{m}{\leftarrow}$ & $\frac{\bar{m}}{\overline{0}}$ & $\begin{array}{l}\frac{0}{0} \\
\frac{0}{0}\end{array}$ & $\begin{array}{c}\frac{N}{N} \\
\stackrel{0}{0}\end{array}$ & $\begin{array}{l}\hat{\circ} \\
\stackrel{0}{0}\end{array}$ & $\frac{\widetilde{N}}{\overparen{0}}$ & 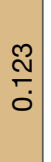 & $\begin{array}{l}\mathscr{D} \\
0 \\
\stackrel{0}{-}\end{array}$ \\
\hline & 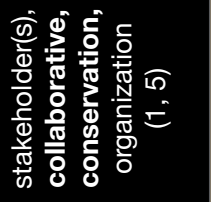 & $\frac{g}{\square}$ & 令 & $\begin{array}{l}\text { م્م } \\
\stackrel{0}{0}\end{array}$ & $\begin{array}{l}\stackrel{9}{0} \\
\stackrel{2}{0} \\
0\end{array}$ & $\begin{array}{l}\stackrel{\infty}{\circ} \\
\stackrel{\circ}{0}\end{array}$ & 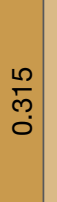 & $\frac{\widehat{\infty}}{0}$ & 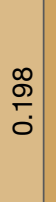 & 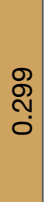 & $\begin{array}{l}\frac{10}{m} \\
\text { Nat }\end{array}$ \\
\hline & 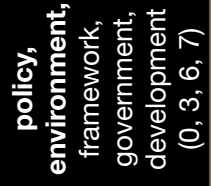 & $\begin{array}{l}\mathfrak{N} \\
\tilde{m} \\
0\end{array}$ & 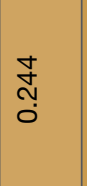 & 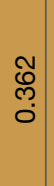 & $\begin{array}{l}\text { o̊ } \\
\text { లె } \\
0\end{array}$ & $\begin{array}{l}\text { ल్ల్ } \\
\text {. }\end{array}$ & 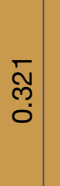 & $\begin{array}{l}0 \\
\frac{0}{0} \\
0 \\
0\end{array}$ & 웅 & 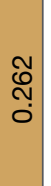 & 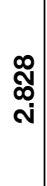 \\
\hline है & 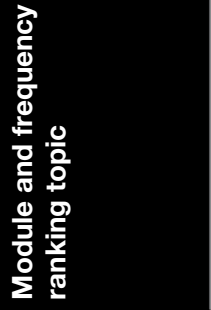 & \begin{tabular}{c} 
aे \\
\hdashline 0 \\
$\vdots$ \\
1 \\
0
\end{tabular} & 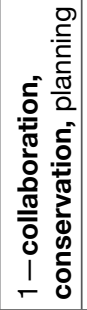 & 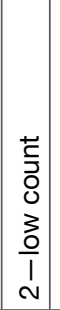 & 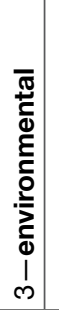 & 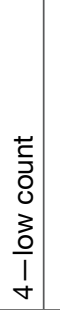 & 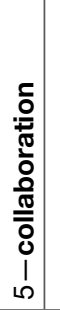 & 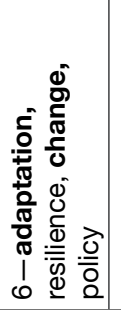 & $\begin{array}{c}\frac{\partial}{0} \\
\frac{0}{0} \\
1 \\
1\end{array}$ & \begin{tabular}{l}
3 \\
\multicolumn{1}{c}{} \\
0 \\
0 \\
3 \\
0 \\
1 \\
$\infty$
\end{tabular} & $\begin{array}{l}\bar{\pi} \\
\stackrel{0}{0}\end{array}$ \\
\hline
\end{tabular}


Social (-Ecological) Network Analysis in Environmental Governance

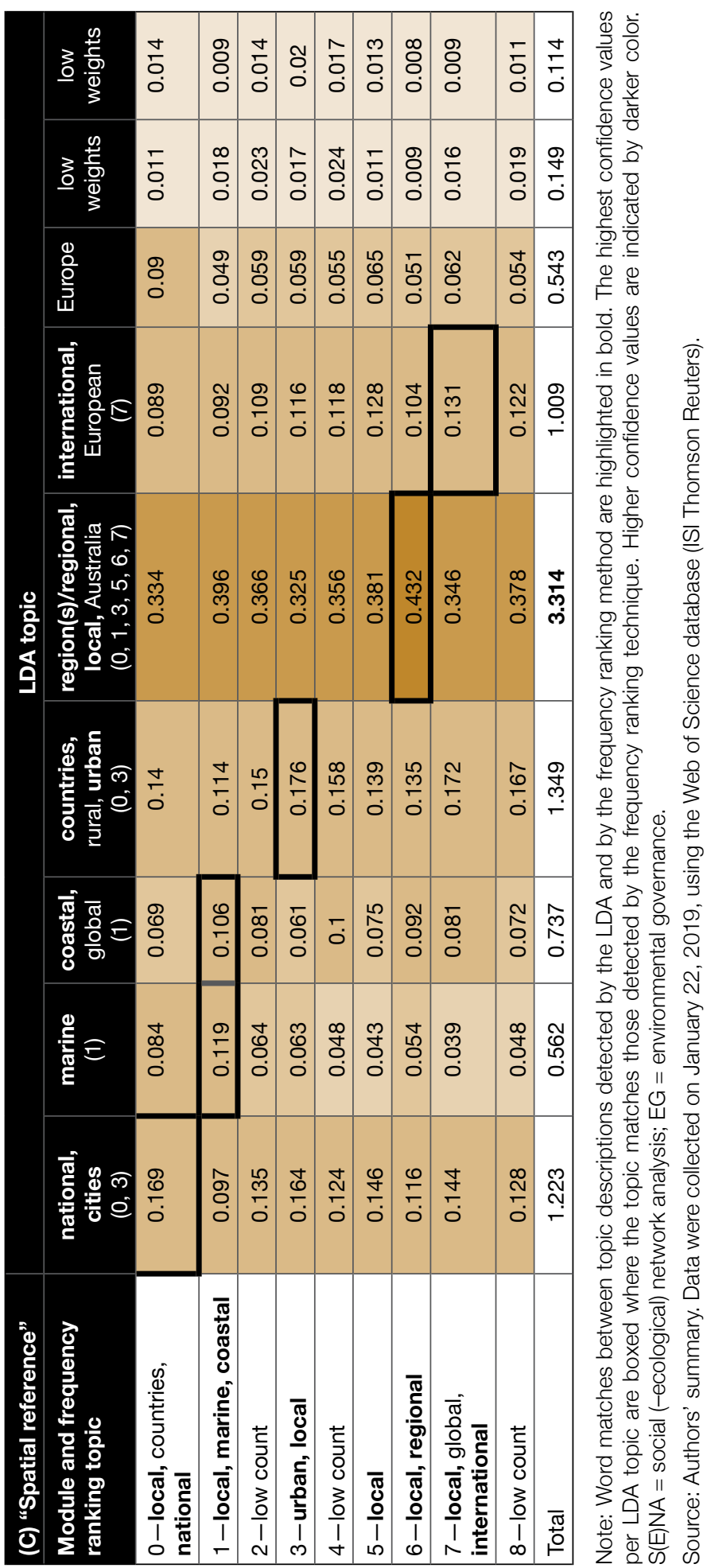




\section{Discussion}

\subsection{Bodies of literature and histogram}

What has been observed as an overwhelming increase in the number of scientific literature within the second half of the last century (Cummings, 1973) and is today culminating in a "publication explosion" (Ware \& Mabe, 2015) is mirrored in the strong rise of all three histograms of scientific fields we represent in Figure 3 from approximately 1980 onwards. While the fields of EG and S(E)NA began to rise in 1910 and 1979 respectively, we find the first record of the application of S(E)NA in EG fairly late, in 2006. The application of S(E)NA in EG is, compared to both research fields observed separately, still nascent and developing. The increasing number of studies applying S(E)NA in EG could imply an increasing importance of network approaches to support and inform decision-making in EG.

\subsubsection{Limitations of our approach to data collection}

During data collection, we may have failed to detect all relevant literature with our search because: (1) we consulted only one database (Web of Science), which represents only a selection of the literature available; (2) our search terms might fail to target a relevant article because the database is missing entries (e.g., missing keywords), or (3) our search terms might fail to match with any word in the abstract, title, or keywords of a relevant article. The articles by Bodin and Crona (2009), Prell et al. (2009), and Folke et al. (2005) provide good examples for this phenomenon. These publications are of high importance to the investigated field of research, S(E)NA in EG, but not listed under the Web of Science results from our search query, as they are not included in the Web of Science selection of journals.

Web of Science results may vary according to an array of conditions. The same query conducted in different libraries or research institutions may produce different search results, due to differences in access. On top of the time lag between the publication of an article and its actual entry in scientific databases, and the selection of journals and articles each database includes (or not), the problem of differences in access further adds to the difficulty of reliably reproducing bibliometric studies.

\subsection{Citation network}

From the 241 publications resulting from our search regarding the application of S(E)NA in EG, only 104 publications cite each other. This means that less than half of the publications influence or are influenced by one or more publications within this field of research. The high number of isolates indicates that the application of $\mathrm{S}(\mathrm{E}) \mathrm{NA}$ in EG is only just beginning to develop into an actual subfield in which publications widely and routinely refer to each other and thus create a distinct field (Zhuge, 2016, Chapter 8). This is corroborated by the fact that authorities in the 
field (Table 4) are relatively recently published (2012 onwards), although one would expect older papers to be the most frequently cited-due to the higher chance of a paper being cited the longer ago it has been published (Adams, 2005).

Investigating the 10 most frequently cited "non-matching" publications revealed that the field S(E)NA in EG is building on literature addressing theories of EG as well as social network theory. Additionally, works that provide practical applications of the analysis of social networks (e.g., software, handbooks) have proven to be of great importance for the emergence of the field (see Figure 4 and Table 5).

The publications included in the citation network contribute the following discoveries and discussions to the field: the effect of social networks on governance capacity (Stein et al., 2011), the combination of SNA with stakeholder analysis (Lienert et al., 2013), the importance of SNA in planning processes (Mills et al., 2014), the use of network analysis in adaptive co-management to facilitate coordination and learning (Cohen et al., 2012), the impact of social networks on resilience and complex resource management (Weiss et al., 2012), the role of central organizations in natural resource governance networks (Fliervoet et al., 2016), the role of socioeconomic-ecological networks for system resilience facing climate change (Luthe et al., 2012), and the relationship between environmental conditions and environmental stewardship networks (Romolini et al., 2013). We assume that these discussions and lines of thought will remain central in the formation of the emerging research field S(E)NA in EG.

Due to their position as hubs in the citation network, several publications can be considered as important storers of knowledge: Galik and Grala (2017), Le et al. (2018), Ruzol et al. (2017), Kuzdas et al. (2015), Muñoz-Erickson and Cutts (2016) Fliervoet et al. (2016), Schoon et al. (2017), and Pietri et al. (2015). They provide a good overview about theory and development of applying S(E)NA in EG. As the hubs are situated closer toward the core of the observed citation network than the authorities, we assume that the authors of these articles are at the moment the best informed ones within the field and thus are able to refer to many different colleagues.

We identify the publications written by Mills et al. (2014), Fliervoet et al. (2016), Borg et al. (2015), Hauck et al. (2015) Bodin et al. (2017), Ingold and Fischer (2014), and Sayles and Baggio (2017) as bridges of knowledge. These publications link different, otherwise unconnected parts of the research field S(E)NA in EG and are important for the formation of a distinct and well-connected field of research, where different theories and lines of thought relate to and inspire each other. As the observed citation network is not very clustered yet, not all bridging positions are very pronounced. Interestingly, five of the seven bridging publications mention collaboration in their titles. Collaboration sticks out as a possibly important interconnecting topic within the research field. Collaboration as a topic could be the context or frame which connects studies that have otherwise different 
focal points. With its high authority score, Mills et al. (2014) is a well-recognized publication within the S(E)NA in EG research community. Mills et al. (2014) list challenges and potential contributions SNA can make to environmental decisionmaking. By reviewing a variety of different sources within the research field, Mills et al. (2014) establish themselves as a bridge of knowledge. Fliervoet et al. (2016) are structurally prominent in all three of our investigated network measures. The article compiles information on relevant network metrics for analyzing natural resource governance. We identify that Fliervoet et al. (2016) is the most central publication in the research field S(E)NA in EG to date and therefore presume that the knowledge transferred by this publication will also remain important for the future development of the field.

\subsubsection{Limitations of the citation network analysis and future work}

As citation records of articles accumulate over time, older publications have a higher chance of being cited. Thereby, the likelihood of reaching a high authority score increases with age. Compared to that, recent articles have a shorter time span in which they might have been recognized and cited by the scientific community. This effect might be less pronounced as digitalization improves. Even so, the identification of authorities is only possible for publications after a certain minimum of time after their publication. Not only age and content, but other factors like language, journal, and open access status might affect authority scores in citation networks, which we did not look at.

\subsection{Similarity network}

The analysis of a large number of scientific publications as a similarity network is helpful as it reduces complexity to a rapidly interpretable degree. By analyzing the similarity network, we could identify different modules in which publication models cluster. These modules clearly exhibit topics differing from the other modules in one or several topic categories. A researcher can take the similarity network maps as guides to the body of literature; to provide a rapid general overview of the field, as well as to indicate literature associated with a specific topic. Publications at the border between two modules are likely to address topical aspects from both modules. Similarly, articles at the center of the network have connections to different modules. They may either cut across topics or deepen a shared underlying topic that is addressed in many other publications (see supplemental material, Table $\mathrm{D}^{14}$ ).

\subsubsection{Developing a classification of module characteristics}

Based on our results, we argue that similarity networks can be characterized on two different levels of topic distribution: (1) on the local (module) level-regarding how topics structure a specific module-and (2) on the global (network) level-

14 See file: Schwenke\&Holzkaemper_SENA in EG Table D_PublicationList.csv (Schwenke \& Holzkämper, 2020). 
regarding how topics influence the overall similarity network. On the local level, a module might feature a single, distinct topic or they might be composed of several less prevalent topics. On the global level, a module might be unique in that its topic does not recur across modules, or a topic might influence the whole network as an underlying topic across modules. In Table 7, we develop an overview of module characteristics on the local and global level.

Table 7. Module characteristics for bibliometric network analysis on the local and global level, as suggested by the authors of this article.

\begin{tabular}{|l|l|}
\hline Local characteristics (module level) \\
\hline distinct & $\begin{array}{l}\text { Dominated by one topic: The module is characterized by a single central, } \\
\text { prevalent topic, indicated by a high number of shared publication topics and } \\
\text { a centralized word frequency (i.e., a large gap between the counts of the most } \\
\text { frequent topic-describing word/s and the less frequent words). }\end{array}$ \\
\hline composite & $\begin{array}{l}\text { Composed of several topics: The module is influenced by several topics, } \\
\text { indicated by a variety of publication topics, each with a relatively low number } \\
\text { of shared publication topics and a distributed word frequency (i.e., a close } \\
\text { distance between the counts of topic-describing words). }\end{array}$ \\
\hline Global module characteristics (network level) \\
\hline discrete & $\begin{array}{l}\text { Not repeating: The module's topic is unique for the whole network, not } \\
\text { recurrent across modules. }\end{array}$ \\
\hline underlying & Repeating: The module's topic is recurrent across two or more modules. \\
\hline
\end{tabular}

Source: Authors' summary.

For the majority of modules, we found the most discrete topic assignments in the "Resources" category, where each module could be assigned an individual topic. The application of S(E)NA in EG spans material resources and their uses and threats, from water, forest, and fisheries to climate, health, and floods/disasters. Modules 5 and 6 include many publications $(5: n=49 ; 6: n=71)$, hence they are big enough for distinct subtopics to emerge. These subtopics can be localized in the network and are characterized by a far lower word frequency than the dominating topic. The largest module $(7: n=83)$, however, is not influenced by a single distinct topic. Rather, this module is composite: it features a collection of topics which are difficult to localize in the network. This also applies to Module 1 and to some degree also to Module 3. These modules might be tied together either by a distinct topic in another topic category or by underlying topics that are also common across modules. The existence of an underlying topic parallel to the discrete "Resources" topics is corroborated by the module topic detection with the LDA technique. LDA identified an underlying topic that strongly influences the network across all modules in the "Resources" category: immaterial resources like information, influence, and knowledge. The detection of this underlying topic strengthens the idea that in the context of EG, independently from the kind of material resource at stake, relations of power and the production of knowledge play a crucial role (Kütting \& Lipschutz, 2009). 
We further detected several distinct topics in the "Governance" and "Spatial reference" categories: Module 1, for example, is composed of several "Resources" topics, but with "collaboration/ conservation" it shows a distinct shared topic in the "Governance" category. This topic, however, is not discrete, but shared across modules. Overall, we find fewer discrete topics in the "Governance" and "Spatial reference" categories than in the "Resources" category: both topic detection methods applied in this study stress the prevalence of underlying topics in these categories. In the "Governance" category, only Modules 6 and 3 feature discrete topics ("adaptation" and "environmental"). "Policy," however, is identified as an underlying topic with the frequency ranking method, and the high LDA confidence value for this topic across all modules agrees with this finding. A similarly high confidence value can be found for the topic "collaboration," which can also be interpreted as an underlying topic for all modules in the governance category. With the exception of Modules 6 and 3, the "Governance" category appears divided into either a "policy" or a "collaboration" focus. We could not explain what causes this divide between "policy" and "collaboration" in the S(E)NA in EG literature that we found by applying our topic detection methods. Rather, we find it debatable if the terms "policy" and "collaboration," which can be filled with a variety of different and contextual meanings, are suitable for discussion in a mere word frequency-based analysis.

In the "Spatial reference" category, several modules show discrete topics (Module 3: "urban," Module 1: "marine/coastal," Module 6: "regional," Module 7: "global” and "international," and Module 0: "countries/nations."). However, all these modules are not only influenced by their discrete topics, but also by the underlying modulecrossing topic "local" - often to a high degree. This finding mirrors the fact that the EG topic focus only recently shifted from local issues to the global (Pattberg $\&$ Widerberg, 2015) and more articles applying S(E)NA in global EG contexts are expected in the future.

\subsubsection{Limitations of the similarity network and LDA and future work}

a) Data preprocessing: For creating the similarity network and for detecting topics, we opted to not include a stemmer for the text data preprocessing. A stemmer maps words with a different ending into a single word and thus accounts for morphological variations of the same word (plural forms, declinations, etc.). Unfortunately, stemming algorithms often reduce words such that their original meaning becomes unintelligible. For example, government and governance would both be reduced to the stem "govern" while having very different meanings. While we could maintain exact word meaning, not including a stemmer resulted in an underestimation of word occurrence, as variations of a word with the same meaning were counted as different words. This has implications for the creation of the similarity matrix (reduced similarity between documents), as well as for the topic detection (lower word counts and weights). 
b) Similarity network creation: In the first step of the similarity network analysis, unrelated articles could be filtered out. By the logic inherent in the cosine similarity, we assumed that the isolates of the similarity network distinctly differed from the rest of the network in their contents. After identifying the content by manually perusing the abstracts of the respective articles, this turned out to be only partially true. The investigation of isolates showed that articles were filtered out although their content was relevant for the network. ${ }^{15}$ The reason for this might be a missing step in the data preprocessing. For cosine similarity calculation, title, abstract, and keywords were each treated as a single text attribute of each document and compared separately. Missing attributes (e.g., missing keywords) can thus create a bias in the data that very likely affected the whole structure of the similarity network we presented. Further, we did not consider a normalization of the similarity network. This may lead to an overrepresentation of publications with a large number of keywords in the data set. However, the bias introduced by the number of keywords may be partially reduced by the fact that we included not only keywords, but also title and abstract to build the similarity network. Therefore, a high total number of words per publication was included. We thus assume that the differences in the number of words per publication are relatively small. Future applications of the method, however, should merge single text attributes of a document before computing cosine similarity. Yet, even after merging text attributes, related articles could still become isolates. A similarity network analysis has to consider the trade-off between a sufficiently high similarity threshold to allow for network structure to emerge and a sufficiently low similarity threshold to include all relevant articles.

c) Topic categories: It is very likely that there exist more topic categories or content levels according to which a similarity network can be analyzed than those we focused on in this study. Although we were guided by the word list with summed word occurrences from all articles, we still heuristically determined the three categories that we focused our analysis on. Several other topic categories may influence clustering; thus it may turn out that single articles of a module are not related to the topic of the module identified for a certain category. Instead, the reason why these seemingly unrelated articles belong to the module may be based on a different topic category. Module 8, for example, is assigned to the "health" topic in the "Resources" category. Yet, only approximately half of these publications actually deal with health. A perusal of abstracts showed that these publications have something else in common: the application of mixed methods approaches to SNA, among them participatory methods such as Net-Map. This exemplifies the relevance of additional topic categories we did not cover in this study. Analyzing the application of different

15 For example, the publication of Schoon et al. (2017), which was identified as a hub in the citation network analysis, but was isolated in the similarity network. 
SNA approaches could (1) give insights to what the overall important methods and metrics applied in EG are and (2) identify whether certain SNA approaches or metrics are applied more often in certain resource or governance contexts.

d) Topic detection methods: We achieved topic detection for this article by two methods: the word frequency ranking and the LDA method. We observed that LDA was less suitable for assigning distinct topics to modules, which could be easily identified by the frequency ranking method. LDA, however, was better in detecting underlying (latent) topics. This is not a surprise, as LDA is mainly designed to detect underlying topics in text (Gropp et al., 2019). With the settings we used in RapidMiner's LDA operator (optimize alpha and beta parameter), we could detect underlying topics, but could also corroborate several distinct topic assignments. We therefore propose that combining the LDA method and the frequency ranking method, as we did in this article, can improve topic detection in a bibliometric analysis of literature. Future research should evaluate the consistency of our results with other types of data sets and LDA settings.

e) Language as a "Bag of Words": Both topic detection methods in this study work with the "Bag of Words" model; that is, disregarding semantic relationships. While we could produce meaningful results in the "Resource" and "Spatial Reference" categories, our methods reached their limits when trying to assess the "Governance" category. This category is unlike the other two categories, because it consists of terms that have different meanings in different contexts. What exactly is meant by "policies" or "collaboration" has to be explained and defined for each study context. Meaning develops in language in more complex ways than with the occurrence of individual nouns, verbs, and adjectives. Language creates meaning by semantic relationships between words. Exactly this type of meaning escapes common topic detection methods by disregarding semantic relationships. These methods can thus only produce informative results where single terms are unambiguous in all contexts.

\section{Conclusion}

The research field S(E)NA in EG is in the process of developing into a distinct field of research where publications frequently relate to each other. To date, Fliervoet et al. (2016) provide a good overview of theories behind EG, ${ }^{16}$ as well as network metrics relevant for the investigation of EG topics. We identified 20 publications which occupy structurally important positions within the research field S(E)NA in EG and recommend the publication of Fliervoet et al. (2016) or one of the other identified central publications (Table 4) to readers aiming to familiarize themselves with the application of $S(E) N A$ in EG.

16 Referred to by Fliervoet et al. (2016) as "natural" governance. 
We see S(E)NA frequently applied in EG contexts such as water, climate, forestry, and fisheries. We propose that a more detailed analysis of the schools of thought, in the course of a citation network analysis, will be helpful to explain why these resource topics are addressed by S(E)NA and others are not. Power structures and the production of knowledge are shared underlying topics for the whole field and S(E)NA in EG literature mainly deals with the local spatial level. Regarding the "Governance" level, part of the S(E)NA in EG literature focuses on the analysis of policies, while another part of the literature more explicitly addresses the analysis of collaboration. "Collaboration" is identified as an important theme by both the citation and the similarity network analysis.

The publication list, citation analysis and science maps developed in this study may help researchers interested in the field to navigate the body of literature, so that they can find literature on S(E)NA in EG more easily in different contextual frameworks. Both the citation and topic detection analysis could further be underpinned by integrating a temporal component: How does the research field develop and how do topics evolve (emerge or become obsolete) over time? Additionally, we propose that future research should investigate the synergies of the LDA method and the frequency ranking method we developed in this study. With this study, we provide a comprehensive methodological approach which generates a first overview of the nascent field of S(E)NA application in EG. We hope to generate impulses that might influence future research to discuss or apply S(E)NA in different EG related specializations under consideration of the literature we present here and thereby to interconnect this growing field further.

\section{References}

Adams, J. (2005). Early citation counts correlate with accumulated impact. Scientometrics, 63, 567-581. doi.org/10.1007/s11192-005-0228-9

Alexander, S. (2015). The ties that bind: Connections, patterns, and possibilities for marine protected areas [Unpublished doctoral dissertation]. University of Waterloo.

Armitage, D., Loë, R. de, \& Plummer, R. (2012). Environmental governance and its implications for conservation practice. Conservation Letters, 5(4), 245-255. doi.org/ 10.1111/j.1755-263X.2012.00238.x

Baggio, J. A., Brown, K., \& Hellebrandt, D. (2015). Boundary object or bridging concept? A citation network analysis of resilience. Ecology and Society, 20(2), Article 2. doi.org/ 10.5751/ES-07484-200202

Balint, P. J., Stewart, R. E., Desai, A., \& Walters, L. C. (2011). Wicked environmental problems: Managing uncertainty and conflict. Island Press. doi.org/10.5822/978-1-61091-047-7 
Barnett, G. A., Huh, C., Kim, Y., \& Park, H. W. (2011). Citations among communication journals and other disciplines: A network analysis. Scientometrics, 88, 449-469. doi.org/ 10.1007/s11192-011-0381-2

Bastian, M., Heymann, S., \& Jacomy, M. (Eds.) (2009). Gephi. (Version 0.9.2) [Computer software]. International AAAI Conference on Weblogs and Social Media. gephi.org/

Blei, D. M., Ng, A. Y., \& Jordan, M. I. (2003). Latent Dirichlet allocation. Journal of Machine Learning Research, 3(Jan), 993-1022. www.jmlr.org/papers/volume3/blei03a/ blei03a.pdf

Blondel, V. D., Guillaume, J.-L., Lambiotte, R., \& Lefebvre, E. (2008). Fast unfolding of communities in large networks. Journal of Statistical Mechanics: Theory and Experiment, 2008, Article P10008. doi.org/10.1088/1742-5468/2008/10/P10008

Bodin, Ö., \& Crona, B. I. (2009). The role of social networks in natural resource governance: What relational patterns make a difference? Global Environmental Change, 19(3), 366-374. doi.org/10.1016/j.gloenvcha.2009.05.002

Bodin, Ö., Sandström, A., \& Crona, B. (2017). Collaborative networks for effective ecosystem-based management: A set of working hypotheses. Policy Studies Journal, 45(2), 289-314. doi.org/10.1111/psj.12146

Bodin, Ö., \& Tengö, M. (2012). Disentangling intangible social-ecological systems. Global Environmental Change, 22(2), 430-439. doi.org/10.1016/j.gloenvcha.2012.01.005

Borg, R., Toikka, A., \& Primmer, E. (2015). Social capital and governance: A social network analysis of forest biodiversity collaboration in Central Finland. Forest Policy and Economics, 50, 90-97. doi.org/10.1016/j.forpol.2014.06.008

Borgatti, S. P., Everett, M. G., \& Freeman, L. C. (2002). UCINET for Windows (Version 6.666) [Computer software]. Analytic Technologies. sites.google.com/site/ucinetsoftware/home

Borrini-Feyerabend, G. (2011). Co-management and shared governance-the "effective and equitable option" for natural resources and protected areas? [Keynote paper]. In D. G. Spelchan, I. A. Nicoll, T. P. H. Nguyen, (Eds.), Co-management/shared governance of natural resources and protected areas in Viet Nam: Proceedings of the National Workshop on Co-management Concept and Practice in Viet Nam, Soc Trang, 17-19 March 2020, pp. 5-26. Deutsche Gesellschaft für Interationale Zussamenarbeit (GIZ [German Organization for International Cooperation]). portals.iucn.org/library/sites/library/files/ documents/Man-Res-597-001.pdf

Bulkeley, H. (2005). Reconfiguring environmental governance: Towards a politics of scales and networks. Political geography, 24(8), 875-902. doi.org/10.1016/j.polgeo.2005.07.002

Chiesura, A., \& Groot, R. de. (2003). Critical natural capital: A socio-cultural perspective. Ecological Economics, 44(2-3), 219-231. doi.org/10.1016/S0921-8009(02)00275-6 
Cohen, P. J., Evans, L. S., \& Mills, M. (2012). Social networks supporting governance of coastal ecosystems in Solomon Islands. Conservation Letters, 5(5), 376-386. doi.org/ 10.1111/j.1755-263X.2012.00255.x

Crona, B., Ernstson, H., Prell, C., Reed, M., \& Hubacek, K. (2011). Combining social network approaches with social theories to improve understanding of natural resource governance. In Ö. Bodin \& C. Prell (Eds.), Social networks and natural resource management: Uncovering the social fabric of environmental governance (pp. 44-72). Cambridge University Press. doi.org/10.1017/CBO9780511894985.004

Cummings, M. M. (1973). Publications: Progress or pollution. American Scientist, 61(2), 163-166. www.jstor.org/stable/27843662

Fliervoet, J. M., Geerling, G. W., Mostert, E., \& Smits, A. J. M. (2016). Analyzing collaborative governance through social network analysis: A case study of river management along the Waal River in The Netherlands. Environmental Management, 57, 355-367. doi.org/10.1007/s00267-015-0606-x

Folke, C., Hahn, T., Olsson, P., \& Norberg, J. (2005). Adaptive governance of socialecological systems. Annual Review of Environment and Resources, 30, 441-473. doi.org/ 10.1146/annurev.energy.30.050504.144511

Freeman, L. C. (1978). Centrality in social networks conceptual clarification. Social Networks, 1(3), 215-239. doi.org/10.1016/0378-8733(78)90021-7

Freeman, L. C., Borgatti, S. P., \& White, D. R. (1991). Centrality in valued graphs: A measure of betweenness based on network flow. Social Networks, 13(2), 141-154. doi.org/10.1016/0378-8733(91)90017-N

Galik, C. S., \& Grala, R. K. (2017). Conservation program delivery in the southern U.S.: Preferences and interactions. Journal of Environmental Management, 198(1), 75-83. doi.org/10.1016/j.jenvman.2017.04.043

Garfield, E. (2004). Historiographic mapping of knowledge domains literature. Journal of Information Science, 30(2), 119-145. doi.org/10.1177/0165551504042802

Glaeser, B. (2016). From global sustainability research matrix to typology: A tool to analyze coastal and marine social-ecological systems. Regional Environmental Change, 16, 367383. doi.org/10.1007/s10113-015-0817-y

Glasbergen, P. (1998). The question of environmental governance. In P. Glasbergen (Ed.), Co-operative environmental governance (pp. 1-18). Springer. doi.org/10.1007/978-94011-5143-6_1

Granovetter, M. S. (1973). The strength of weak ties. American Journal of Sociology, 78(6), 1360-1380. doi.org/10.1086/225469 
Gropp, C., Herzog, A., Safro, I., Wilson, P. W., \& Apon, A. W. (2019). Clustered latent Dirichlet allocation for scientific discovery. In C. Baru, (Ed.), 2019 IEEE International Conference on Big Data: Proceedings (pp. 4503-4511). IEEE (Institute of Electrical and Electronics Engineers). doi.org/10.1109/BigData47090.2019.9005964

Hanneman, R. A., \& Riddle, M. (2005). Introduction to social network methods [Online book]. University of California, Riverside. www.faculty.ucr.edu/ -hanneman/nettext/

Hauck, J., Stein, C., Schiffer, E., \& Vandewalle, M. (2015). Seeing the forest and the trees: Facilitating participatory network planning in environmental governance. Global Environmental Change, 35, 400-410. doi.org/10.1016/j.gloenvcha.2015.09.022

Huang, A. (2008, April 14-18). Similarity measures for text document clustering [Paper presentation]. Sixth New Zealand Computer Science Research Student Conference (NZCSRSC2008). University of Canterbury, Christchurch, New Zealand.

Ingold, K., \& Fischer, M. (2014). Drivers of collaboration to mitigate climate change: An illustration of Swiss climate policy over 15 years. Global Environmental Change, 24, 88-98. doi.org/10.1016/j.gloenvcha.2013.11.021

Jacomy, M., Venturini, T., Heymann, S., \& Bastian, M. (2014). ForceAtlas2, a continuous graph layout algorithm for handy network visualization designed for the Gephi software. PloS ONE, 9(6), e98679. doi.org/10.1371/journal.pone.0098679

Kleinberg, J. M. (1999). Authoritative sources in a hyperlinked environment. Journal of the ACM, 46(5), 604-632. doi.org/10.1145/324133.324140

Kütting, G., \& Lipschutz, R. (Eds.). (2009). Environmental governance: Power and knowledge in a local-global world [eBook]. Routledge. doi.org/10.4324/9780203880104

Kuzdas, C., Wiek, A., Warner, B., Vignola, R., \& Morataya, R. (2015). Integrated and participatory analysis of water governance regimes: The case of the Costa Rican dry tropics. World Development, 66, 254-268. doi.org/10.1016/j.worlddev.2014.08.018

Larsen, B., \& Aone, C. (1999). Fast and effective text mining using linear-time document clustering. In Proceedings of the fifth ACM SIGKDD International Conference on Knowledge Discovery and Data Mining (KDD '99) (pp. 16-22). Association for Computing Machinery. doi.org/10.1145/312129.312186

Le, N., Nguyen, T., \& Zhu, D. (2018). Understanding the stakeholders' involvement in utilizing municipal solid waste in agriculture through composting: A case study of Hanoi, Vietnam. Sustainability 10(7), Article 2314. doi.org/10.3390/su10072314

Lebel, L., Anderies, J. M., Campbell, B., Folke, C., Hatfield-Dodds, S., Hughes, T. P., $\&$ Wilson, J. (2006). Governance and the capacity to manage resilience in regional social-ecological systems. Ecology \& Society, 11(1), Article 19. doi.org/10.5751/ES01606-110119 
Lee, M. (2003, May 3-5). Conceptualizing the new governance: A new institution of social coordination [Paper presentation]. Institutional Analysis and Development MiniConference, Indiana University, Bloomington, Indiana, USA.

Leydesdorff, L. (2007). Betweenness centrality as an indicator of the interdisciplinarity of scientific journals. Journal of the American Society for Information Science and Technology, 58(9), 1303-1319. doi.org/10.1002/asi.20614

Lienert, J., Schnetzer, F., \& Ingold, K. (2013). Stakeholder analysis combined with social network analysis provides fine-grained insights into water infrastructure planning processes. Journal of Environmental Management, 125, 134-148. doi.org/10.1016/ j.jenvman.2013.03.052

Luthe, T., Wyss, R., \& Schuckert, M. (2012). Network governance and regional resilience to climate change: Empirical evidence from mountain tourism communities in the Swiss Gotthard region. Regional Environmental Change, 12, 839-854. doi.org/10.1007/ s10113-012-0294-5

Marin, A., \& Wellman, B. (2014). Social network analysis: An introduction. In J. Scott \& P. Carrington (Eds.) The SAGE Handbook of Social Network Analysis. SAGE Publications. dx.doi.org/10.4135/9781446294413.n2

Mierswa, I., \& Klinkenberg, R. (2018). RapidMiner Studio (9.3) [Data science, machine learning, predictive analytics]. Retrieved from rapidminer.com/

Mills, M., Álvarez-Romero, J. G., Vance-Borland, K., Cohen, P., Pressey, R. L., Guerrero, A. M., \& Ernstson, H. (2014). Linking regional planning and local action: Towards using social network analysis in systematic conservation planning. Biological Conservation, 169, 6-13. doi.org/10.1016/j.biocon.2013.10.015

Muñoz-Erickson, T. A., \& Cutts, B. B. (2016). Structural dimensions of knowledge-action networks for sustainability. Current Opinion in Environmental Sustainability, 18, 56-64. doi.org/10.1016/j.cosust.2015.08.013

Nakazawa, R., Itoh, T., \& Saito, T. (2018). Analytics and visualization of citation network applying topic-based clustering. Journal of Visualization, 21, 681-693. doi.org/10.1007/ s12650-018-0483-5

Ostrom, E. (1990). Governing the commons: The evolution of institutions for collective action. Cambridge University Press. doi.org/10.1017/CBO9780511807763

Paavola, J. (2007). Institutions and environmental governance: A reconceptualization. Ecological Economics, 63(1), 93-103. doi.org/10.1016/j.ecolecon.2006.09.026

Pattberg, P., \& Widerberg, O. (2015). Theorising global environmental governance: Key findings and future questions. Millennium, 43(2), 684-705. doi.org/10.1177/ 0305829814561773 
Pietri, D. M., Stevenson, T. C., \& Christie, P. (2015). The Coral Triangle Initiative and regional exchanges: Strengthening capacity through a regional learning network. Global Environmental Change, 33, 165-176. doi.org/10.1016/j.gloenvcha.2015.05.005

Prell, C., Hubacek, K., \& Reed, M. (2009). Stakeholder analysis and social network analysis in natural resource management. Society \& Natural Resources, 22(6), 501-518. doi.org/ $10.1080 / 08941920802199202$

Romolini, M., Grove, J. M., \& Locke, D. H. (2013). Assessing and comparing relationships between urban environmental stewardship networks and land cover in Baltimore and Seattle. Landscape and Urban Planning, 120, 190-207. doi.org/10.1016/j.landurbplan. 2013.08.008

Ruzol, C., Banzon-Cabanilla, D., Ancog, R., \& Peralta, E. (2017). Understanding water pollution management: Evidence and insights from incorporating cultural theory in social network analysis. Global Environmental Change, 45, 183-193. doi.org/10.1016/ j.gloenvcha.2017.06.009

Sayles, J. S., \& Baggio, J. A. (2017). Who collaborates and why: Assessment and diagnostic of governance network integration for salmon restoration in Puget Sound, USA. Journal of Environmental Management, 186(Part 1), 64-78. doi.org/10.1016/j.jenvman. 2016.09.085

Schoon, M., York, A., Sullivan, A., \& Baggio, J. (2017). The emergence of an environmental governance network: The case of the Arizona borderlands. Regional Environmental Change, 17, 677-689. doi.org/10.1007/s10113-016-1060-x

Schwenke, T., \& Holzkämper, E. (2020). Social (-ecological) network analysis in environmental governance-central publications, important concepts and areas of application data collected in January 2019 [Data set]. doi.org/10.5281/zenodo.4266382

Scott, J. (2000). Social network analysis: A Handbook (2nd ed.). Sage Publishing. (Original work published 1991; further editions published 2012, 2017.)

Scott, M. (2015). Re-theorizing social network analysis and environmental governance: Insights from human geography. Progress in Human Geography, 39(4), 449-463. doi.org/ $10.1177 / 0309132514554322$

Shaw, R. (1981). Strange attractors, chaotic behavior, and information flow. Zeitschrift für Naturforschung A, 36(1), 80-112. doi.org/10.1515/zna-1981-0115

Small, H., Boyack, K. W., \& Klavans, R. (2014). Identifying emerging topics in science and technology. Research Policy, 43(8), 1450-1467. doi.org/10.1016/j.respol.2014.02.005

Stein, C., Ernstson, H., \& Barron, J. (2011). A social network approach to analyzing water governance: The case of the Mkindo catchment, Tanzania. Physics and Chemistry of the Earth, 36(14-15), 1085-1092. doi.org/10.1016/j.pce.2011.07.083 
van Eck, N. J., \& Waltman, L. (2014). CitNetExplorer: A new software tool for analyzing and visualizing citation networks. Journal of Informetrics, 8(4), 802-823. doi.org/10.1016/ j.joi.2014.07.006

Venturini, T., Jacomy, M., \& Pereira, D. (2015). Visual network analysis: The example of the Rio 20 online debate (Working paper). Sciences Po Paris médialab. spire.sciencespo.fr/ hdl:/2441/1698ddv85d9ffo13hjld5iudlo/resources/visualnetwork-paper-10.pdf

Ware, M., \& Mabe, M. (2015). The STM report: An overview of scientific and scholarly journal publishing (4th ed.). International Association of Scientific, Technical and Medical Publishers. www.stm-assoc.org/2015_02_20_STM_Report_2015.pdf

Wasserman, S., \& Faust, K. (1994). Social network analysis: Methods and applications. Cambridge University Press. doi.org/10.1017/CBO9780511815478

Weiss, K., Hamann, M., Kinney, M., \& Marsh, H. (2012). Knowledge exchange and policy influence in a marine resource governance network. Global Environmental Change, 22(1), 178-188. doi.org/10.1016/j.gloenvcha.2011.09.007

Wijkman, A., \& Rockström, J. (2013). Bankrupting nature: Denying our planetary boundaries. Routledge. doi.org/10.4324/9780203107980

Young, O. R. (2016). On environmental governance: Sustainability, efficiency, and equity. Routledge. doi.org/10.4324/9781315633176

Zhang, Y., Jin, R., \& Zhou, Z. H. (2010). Understanding bag-of-words model: A statistical framework. International Journal of Machine Learning and Cybernetics, 1, 43-52. doi.org/ 10.1007/s13042-010-0001-0

Zhuge, H. (2016). Multi-dimensional summarization in cyber-physical society. Elsevier. doi.org/ 10.1016/B978-0-12-803455-2.00008-1 
This text is taken from Human Ecology Review, Volume 26, Number 2, 2020, published by ANU Press, The Australian National University, Canberra, Australia. doi.org/10.22459/HER.26.02.2020.06 